\title{
Annual and Interannual Changes in the North Atlantic STMW Layer Properties
}

\author{
Michael A. Alfultis* and Peter Cornillon \\ University of Rhode Island, Graduate School of Oceanography, Narragansett, Rhode Island
}

(Manuscript received 9 August 1999, in final form 29 September 2000)

\begin{abstract}
Subtropical mode waters (STWMs) are water masses formed in winter by convective mixing on the equatorward side of western boundary currents in the subtropical gyres. After the return of the seasonal stratification in spring, it is found at the stratification minimum between the seasonal and main pycnoclines. By characterizing STMW primarily at the density gradient minimum, previous studies were limited in their ability to describe STMW properties over large temporal and spatial scales. Rather than using a density-based characterization, the North Atlantic STMW layer was identified here by its much smaller temperature gradient relative to the more stratified seasonal and main thermocline, its temperature, and its large thickness. By using this temperaturebased characterization, this study was able to develop a climatology using the large number of XBTs deployed between 1968 and 1988 and contained in the World Ocean Atlas 1994 historical hydrographic database and to use this climatology to examine STMW properties on large spatial and long temporal scales. Three different characterizations were used to assess the degree of convective renewal of the STMW layer during the 196888 winters. Two characterizations were based on comparing the winter mixed layer properties to the STMW layer properties in the previous fall, while the third characterization involved comparing the temperature gradient through the STMW layer in the spring to the STMW layer temperature gradient in the previous fall. Based on these characterizations, there was considerable spatial and temporal variability in the renewal of the STMW layer's vertical homogeneity from 1968 to 1988. Basinwide renewal occurred in 1969, 1970, 1977, 1978, 1981, and 1985 , with more localized renewal, usually east of $55^{\circ} \mathrm{W}$, in the other years. While STMW is nearly vertically homogeneous immediately after renewal, the temperature gradient through the layer increases with time following renewal. The annual rate of increase in the temperature gradient in the year following renewal is $\sim 5-6$ ( $\times$ $10^{-4}{ }^{\circ} \mathrm{C}$ per $100 \mathrm{~m}$ per day), while the interannual rate of increase is $\sim 2.0 \times 10^{-4}{ }^{\circ} \mathrm{C}$ per $100 \mathrm{~m}$ per day following winters with no renewal of the STMW layer.
\end{abstract}

\section{Introduction}

Subtropical mode waters (STMWs) are water masses located between the seasonal and main thermoclines in the northwestern and central portions of the subtropical gyres (Schroeder et al. 1959; Suga and Hanawa 1990; Qiu and Joyce 1992). The STMW in the North Atlantic is centered at $\sim 300 \mathrm{~m}$ with typical thicknesses of 200 $\mathrm{m}$ (Schroeder et al. 1959; Worthington 1959; Istoshin 1961; Leetmaa 1977; Worthington 1977; Talley and Raymer 1982; Ebbesmeyer and Lindstrom 1986; Taft et al. 1986), and is classically defined by temperatures ranging from $17.6^{\circ}$ to $18.2^{\circ} \mathrm{C}$ (Worthington 1959), salinities 36.4 to 36.6 psu (Schroeder et al. 1959; Worthington 1959), and potential densities at its core $\sim 26.4$ $\mathrm{kg} \mathrm{m}^{-3}$ (Worthington 1959; Talley and Raymer 1982).

\footnotetext{
*Current affiliation: Department of Science, U.S. Coast Guard Academy, New London, Connecticut.

Corresponding author address: Michael Alfultis, Department of Science, U.S. Coast Guard Academy, 27 Mohegan Avenue, New London, CT 06320-8101.

E-mail: malfultis@cga.uscg.mil
}

Since the core temperature is very nearly $18^{\circ} \mathrm{C}$, North Atlantic STMW is often referred to as "Eighteen Degree Water" (Schroeder et al. 1959; Worthington 1959; Ebbesmeyer and Lindstrom 1986).

These water masses are generally understood to form in late winter when atmospheric cooling removes the seasonal stratification, exposing thick well-mixed layers on the equatorward side of separated western boundary currents to further cooling and convective mixing (McCartney 1982; Talley and Raymer 1982; Ebbesmeyer and Lindstrom 1986). With the return of the seasonal thermocline in spring, the STMW layer can be identified as a layer of high oxygen content and minimum stratification due to the convective nature of its formation (Worthington 1959; McCartney et al. 1980; McCartney 1982; Talley and Raymer 1982; Ebbesmeyer and Lindstrom 1986).

The degree of STMW formation/renewal varies considerably from one winter to the next. By looking at the changes in salinity along isopycnals, Jenkins (1982) found that the annual STMW renewal rate varied by as much as a factor of 2 between 1954 and 1980. The STMW layer is known to have undergone significant, large-scale renewal in the mid and late 1960s, 1977, and 
1982, with less to no renewal in other winters (through 1988) (McCartney et al. 1980; Jenkins 1982; Talley and Raymer 1982; Klein and Hogg 1996; Jenkins 1998). Jenkins (1982) and Hazeleger and Drijfhout (1998) suggest that the STMW layer responds rapidly to the largescale convective events, which set its core properties and that its properties relax more slowly during years of poor ventilation. Based on their numerical model results, Hazeleger and Drijfhout (1998) explained Jenkin's "interannual memory" in terms of the anomously strong stratification induced by a winter of severe cooling and the establishment of the seasonal pycnocline in following spring/summer. This strong stratification helps preserve the STMW layer underneath. They found it took five years for the potential vorticity of the STMW layer to return to its climatological value following an anomously cold winter. Because of this "storage mechanism," several consecutive cold winters can produce a persistent anomolous STMW layer that a single "normal" or warm winter cannot attenuate. The STMW layer, then, contains an interannual memory of the degree of ventilation/renewal that the subtropical gyre experiences down to the main thermocline in a particular winter (Jenkins 1982; Woods and Barkmann 1986; Roemmich and Cornuelle 1992).

While a direct connection between the interannual variability in STMW properties and the ocean-atmosphere heat flux has been difficult to establish (Jenkins 1982; Talley and Raymer 1982; Hanawa and Hoshino 1988), several authors have commented on the similarity in the patterns of the atmospheric forcing, surface heat loss, SST anomalies, and/or STMW properties. Cayan (1992) established the changes in the surface heat flux act to drive changes in the SST, particularly in the subtropical gyre in winter, and that this connection between the heat flux and SST anomalies is driven by changes in the large-scale atmospheric forcing patterns such as the North Atlantic Oscillation (NAO) in the Atlantic and the Pacific-North American teleconnection (PNA) in the Pacific. Yasuda and Hanawa (1999) found that the North Pacific STMW properties in a given year are determined by the atmospheric patterns associated with the East Asian monsoon through changes in the Ekmandriven heat transport in the surface layer and through changes in the heat loss through the surface. While they found these two processes of equal importance in determining the interannual variations of STMW properties, they found the changes in the Ekman-driven heat transport to be the primary factor in determining decadal changes or shifts in North Pacific STMW properties with surface heat loss of secondary importance (Yasuda and Hanawa 1997). They related the decadal changes in North Pacific STMW properties to changes in the atmospheric forcing patterns, namely the PNA (Yasuda and Hanawa 1997), while Dickson et al. (1996) related decadal changes in North Atlantic STMW properties to changes in the NAO. Several numerical modeling studies have also successfully related variations in the
STMW properties to atmospheric forcing (Marsh and New 1996; Hazeleger and Drijfhout 1998; Paiva and Chassignet 2000).

In addition to variations in the atmospheric circulation patterns, changes in the oceanic circulation patterns will also strongly influence the interannual variability of STMW properties by determining whether the STMW properties formed in a given winter will be incorporated into the subtropical gyre circulation or be advected out of the gyre (Woods and Barkmann 1986; Klein and Hogg 1996; Yasuda and Hanawa 1999). Joyce and Robbins (1996) found that the temperature and salinity anomalies of the surface layer $(0-200 \mathrm{~m})$ at the Panulirus station are uncorrelated, the salinity anomalies in this layer have a longer timescale than the temperature anomalies, and the periods of positive salinity anomaly in this layer corresponded to periods of low potential vorticity (renewal) in the STMW layer. They then suggest that other factors in addition to atmospheric forcing such as precipitation, runoff, or intergyre exchange with the subpolar North Atlantic could play important roles in renewal of the STMW layer.

The previous studies of the STMW layer interannual variability were based on the Panulirus hydrographic dataset collected in the vicinity of Bermuda, a single point in space (Talley and Raymer 1982; Klein and Hogg 1996), and numerical model results (Marsh and New 1996; Hazeleger and Drijfhout 1998). The goal here is to examine the annual and interannual variability in STMW properties using a climatology of the STMW layer constructed from hydrographic station, conductivity/temperature/depth, and expendable bathythermograph data and described in the companion to this paper (Alfultis and Cornillon 2001). The data, data processing, and method used to identify the STMW layer are briefly summarized in the next section. The reader is referred to Alfultis (1997) and Alfultis and Cornillon (2001) for a more detailed discussion. Following this brief description, the degree of STMW renewal during the 1968-88 winters is characterized by comparing the winter mixed layer properties to the STMW layer properties in the following summer and previous fall. The variation in the degree of renewal with longitude will also be described. Finally, the annual and interannual variability in the STMW layer temperature, temperature gradient, and thickness and how the variability changes with longitude are discussed.

\section{Determining the STMW layer and assembling the STMW climatologies}

\section{a. Profile selection and correction}

The hydrographic data used in this study consisted of station, CTD/STD, and XBT data from the World Ocean Atlas 1994 (WOA94) (Boyer and Levitus 1994) and station data from the Russian Long-term Research on Hydrometeorological Anomalies and Sections re- 
search programs (Lappo et al. 1995). Processing of these data began with the removal of duplicate profiles and profiles flagged by the NODC Ocean Climate Laboratory (OCL) as coming from cruises with consistently poor quality control. Any observation in a profile flagged by the OCL as an outlier, a large temperature inversion, or a large temperature gradient was removed from the profile. Next, only profiles in the subtropical gyre seaward of the Gulf Stream, north of $25^{\circ} \mathrm{N}$ and west of $40^{\circ} \mathrm{W}$, and hence likely to have sampled the STMW layer were selected.

The OCL's drop-rate correction was then applied to all XBTs shallower than $800 \mathrm{~m}$ to correct for the fact that, in general, they fall faster than the published drop rates (Hanawa and Yoritaka 1987; Singer 1990; Hanawa and Yoshikawa 1991; Hallock and Teague 1992; Hanawa et al. 1995). Spikes thought to result from instrument noise were then removed from the XBT profiles, and "large" density inversions were removed from all station and CTD profiles. Finally, profiles with inadequate vertical sampling at typical STMW depths were eliminated from the dataset.

\section{b. Identifying the STMW layer}

The STMW layer is commonly identified as the stratification/potential vorticity minimum between the seasonal and permanent pycnoclines (McCartney 1982; Talley and Raymer 1982; Ebbesmeyer and Lindstrom 1986; Klein and Hogg 1996). In this study, however, we developed a technique to identify and characterize the STMW layer that relied solely on temperature profiles, allowing us to take advantage of the fact that there are over seven times the number of useable XBT profiles compared with the number of CTD and station profiles.

A profile was said to have a STMW layer if it met one or both of two sets of criteria: First, the deepest layer at least $95 \mathrm{~m}$ thick, with temperatures between $16.5^{\circ}$ and $19.5^{\circ} \mathrm{C}$ and temperature gradients between adjacent pairs of points less than or equal to $0.95^{\circ} \mathrm{C}$ per $100 \mathrm{~m}$, was identified as a candidate STMW layer. The second method identified as a possible STMW layer the thickest layer exceeding $95 \mathrm{~m}$ with temperatures between $16.5^{\circ}$ and $19.5^{\circ} \mathrm{C}$ and a temperature difference through the layer less than or equal to $0.95^{\circ} \mathrm{C}$. These values were chosen based on Talley and Raymer (1982), Hall and Fofonoff (1993), and Klein and Hogg (1996) to identify the general part of the water column containing STMW without biasing any subsequent results. When the layers identified by the two methods differed, the thickest layer encompassing both layers was chosen as a candidate STMW layer. If neither method could identify a layer with these characteristics, the profile was rejected. Two tests were then performed on points in the vicinity of the top and bottom of the candidate STMW layer to determine if adding or removing these points would make a more uniform STMW layer.

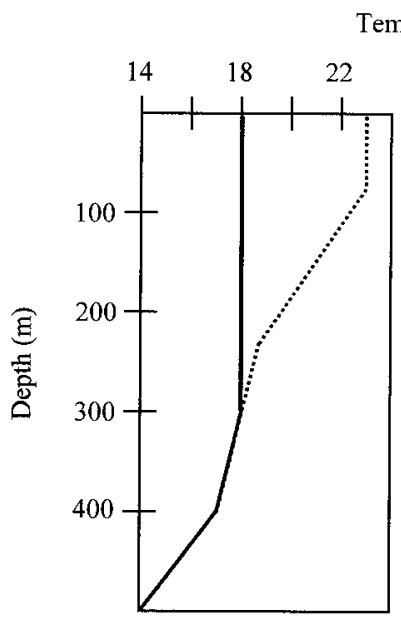

(a)

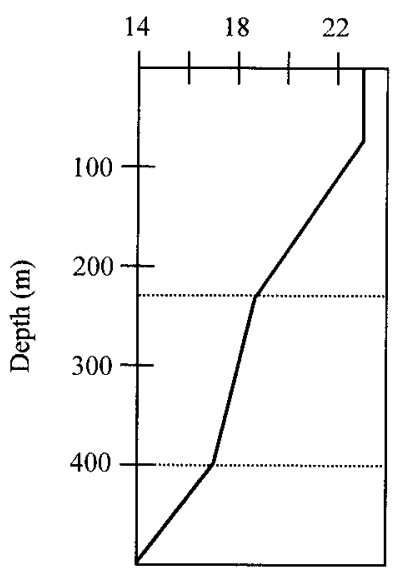

(c) emperature (C)

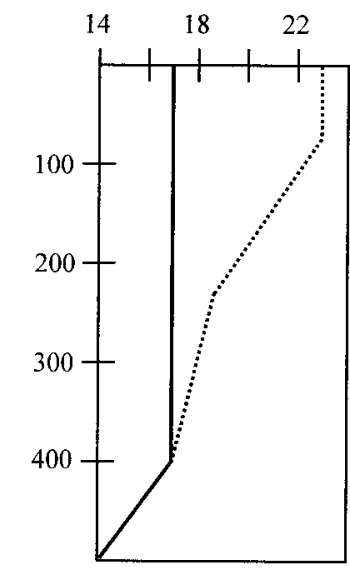

(b)

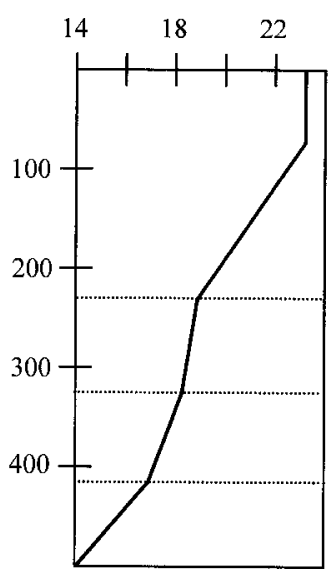

(d)
FIG. 1. Four possible STMW configurations: (a) wintertime convective mixing partially penetrates and renews the layer, (b) wintertime convective mixing renews entire layer, (c) single STMW layer between seasonal and permanent thermoclines, and (d) dual STMW layer between seasonal and permanent thermoclines.

The STMW layer can exist in one of four different configurations (Fig. 1):

1) a STMW layer with all of the seasonal stratification removed and a thickening mixed layer above,

2) convective mixing has completely renewed/ventilated the STMW layer,

3) a single STMW layer with an overlying seasonal thermocline and mixed layer,

4) a dual-layer STMW layer between the seasonal and permanent thermoclines.

Using the method described above, we were able to identify the STMW layer in the first three configurations. This method would identify the two STMW layers in the last configuration as a single, thick STMW layer because it could not distinguish the newly formed STMW layer from the preexisting STMW layer due the 
small differences in the temperature and temperature gradient of each layer.

\section{c. Determining STMW layer properties}

STMW layer properties obtained from the profiles were the depths of the top and bottom of the STMW layer, the temperatures at the top and bottom of the layer, and the temperature gradient through the layer, the latter being determined from the slope of a least squares line fit to the data points in the most uniform layer. The depth and temperature at the bottom of the STMW layer were determined when the maximum depth of the profile was greater than $600 \mathrm{~m}$, provided that the bottom of the STMW layer was found before the end of the profile. The potential vorticity of the STMW layer was also determined from station and CTD profiles meeting these two criteria. Since XBT profiles constitute the bulk of the data in the WOA and most of these $(\sim 2 / 3)$ are shallower than $600 \mathrm{~m}$, the uncertainties in the properties at the bottom of the STMW layer will be larger than the properties at the top of the layer.

The selected hydrographic data are unevenly distributed in space and time. To find an unbiased estimate of the STMW layer properties, all profiles thought to be spatially and temporally correlated (collected within 75 $\mathrm{km}$ and 10 days of each other) were grouped into one cluster using an agglomerative hierarchical clustering algorithm (Gong and Richman 1995) and averaged to yield one independent observation. The mean values for a given area were determined from the weighted mean of all independent observations (clusters and other independent profiles not falling within a cluster) in that area. The estimated error of each cluster mean or individual profile was used as the weighting factor:

$$
\bar{X}=\frac{\sum_{i=1}^{N} \frac{x_{i}}{\sigma_{i}^{2}}}{\sum_{i=1}^{N} \frac{1}{\sigma_{i}^{2}}}
$$

where $\bar{X}$ is the mean value for a given area, $x_{i}$ is $i$ th independent observation (cluster mean or individual profile), $\sigma_{i}$ is the estimated error of the $i$ th independent observation, and $N$ is the number of independent observations in the given area. The uncertainty of the mean $\left(\sigma_{\bar{X}}^{2}\right)$ is then given by

$$
\frac{1}{\sigma_{\bar{X}}^{2}}=\sum_{i=1}^{N} \frac{1}{\sigma_{i}^{2}} .
$$

\section{Characterizing STMW renewal events}

In this section, the interannual and spatial variations in the degree of STMW renewal are characterized for the years 1968-88. These years were chosen based on data availability. For the purposes of this paper, winter will be defined as extending from February to April when SSTs in the North Atlantic subtropical gyre are typically near their minimum, spring as May to July when SSTs are increasing, summer as August to October when SSTs are typically near their maximum, and fall as November to January when SSTs are decreasing. The STMW renewal events will be characterized using three criteria. The first two involve comparing the winter mixed layer depths and temperatures to the depths and temperatures at the top of the STMW layer in the previous fall, prior to its exposure to direct atmospheric cooling. The differences in temperature and depth of the winter mixed layer and the top of the preexisting STMW layer will indicate the degree to which winter convective mixing penetrated the STMW layer. If the winter mixed layers were colder/deeper than the top of the STMW layer in the previous fall, the winter mixed layers likely penetrated into the STMW layer, and the STMW layer experienced some degree of convective mixing during that winter. Conversely, if the winter mixed layers were warmer/shallower than the top of the preexisting STMW layer and thus did not penetrate into the STMW layer, then the STMW layer experienced little or no convective mixing that winter. The third criterion is based on the temperature gradient through the STMW layer in spring, just after the return of the seasonal stratification. If the mean temperature gradient in spring is less than it was in the previous fall, it will be assumed that this decrease was the result of STMW formation that resulted in a thicker and/or more vertically homogeneous STMW layer. Conversely, a mean temperature gradient in spring equal to or greater than its mean value in the previous fall most likely means the STMW layer has become thinner and/or more stratified and was therefore not exposed to direct atmospheric cooling in winter.

Because the hydrographic data are unevenly distributed in space and time, plots of the location of winter and spring profiles were first generated to visualize the data distribution from one year to the next. The symbols used to indicate the profile positions in these diagrams were plotted with a color scale to indicate the character of the mixed layer each winter and the STMW layer each spring. The color scale in Figs. 2 and 3 indicates the depth and temperature differences between the plotted winter mixed layers and the mean top of the STMW layer the previous fall before the STMW layer is exposed to direct atmospheric cooling. The mean depth and temperature at the top of the STMW layer in the previous fall were determined by averaging over regions with sufficient data points to provide a reliable estimate while at the same time allowing for an estimate of the spatial variability of these quantities. Specifically, although the clustering of profiles close in space and time done here (section $2 \mathrm{c}$ ) will reduce some of the bias toward regions and times with large data densities, it is evident from Figs. 2-4 that any averaging will be biased toward the west. Therefore, the mean depth and temperature at the top of the STMW layer in the previous 

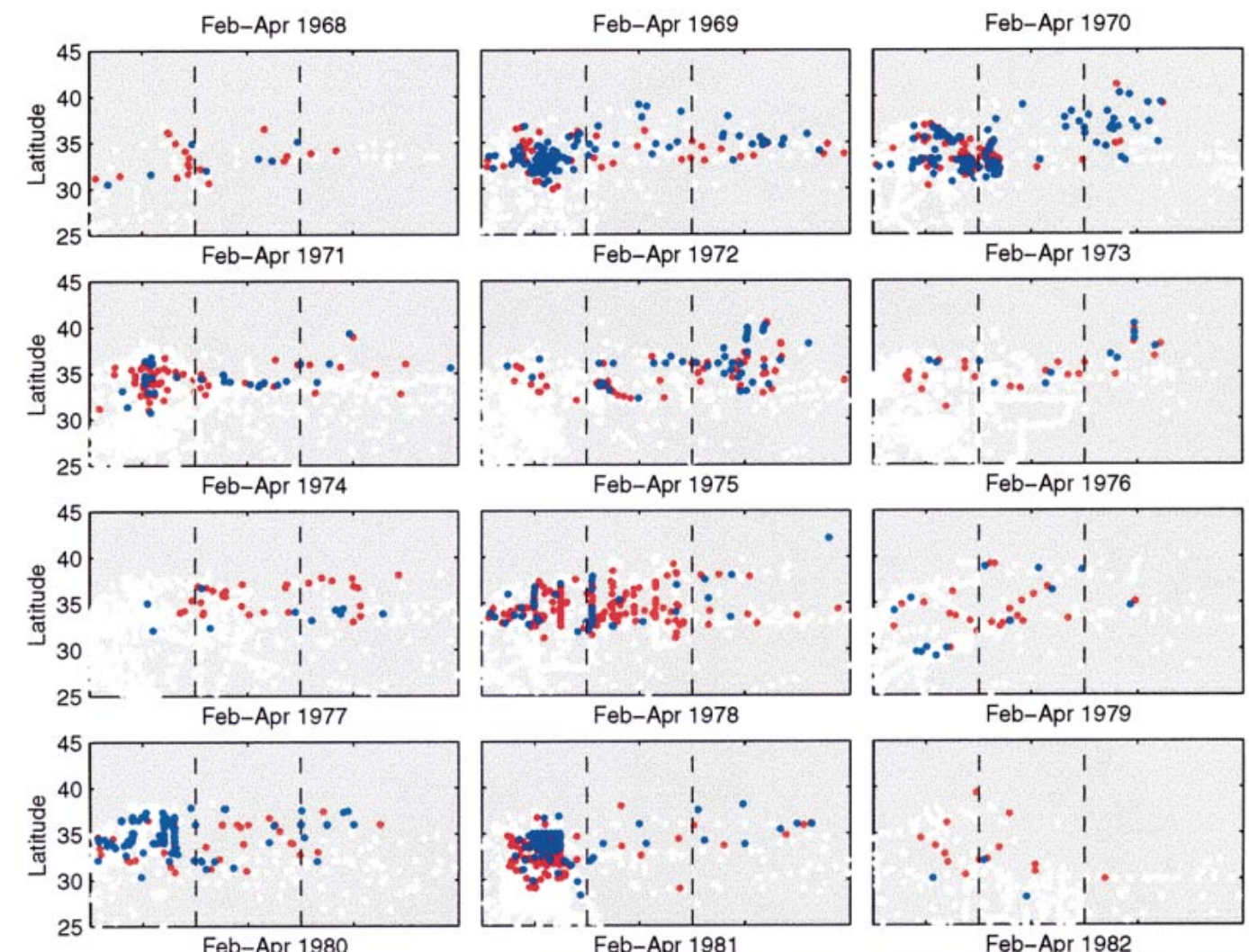

Feb-Apr 1979
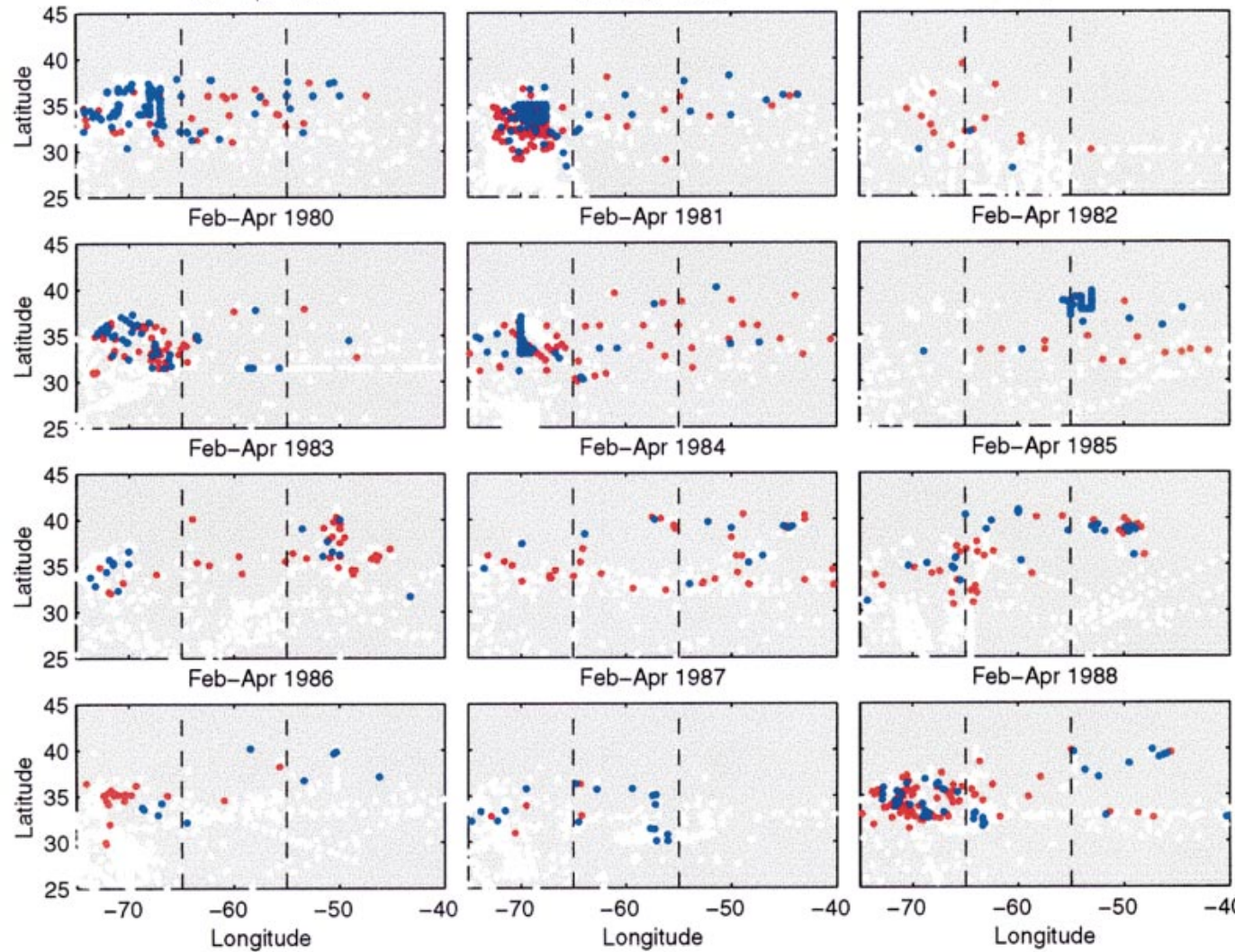

Feb-Apr 1988

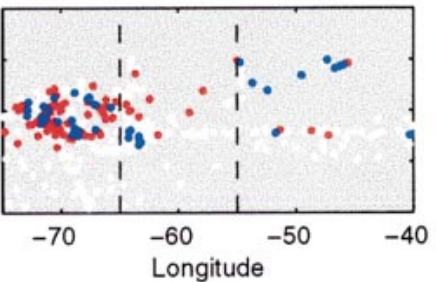

0

$0-100$

$>100$

FIG. 2. Feb-Apr profile positions. Symbol used to plot each profile position has been shaded to indicate the difference (in $\mathrm{m}$ ) between the profile's mixed layer depth and the previous fall's STMW layer top depth. See text for details. 

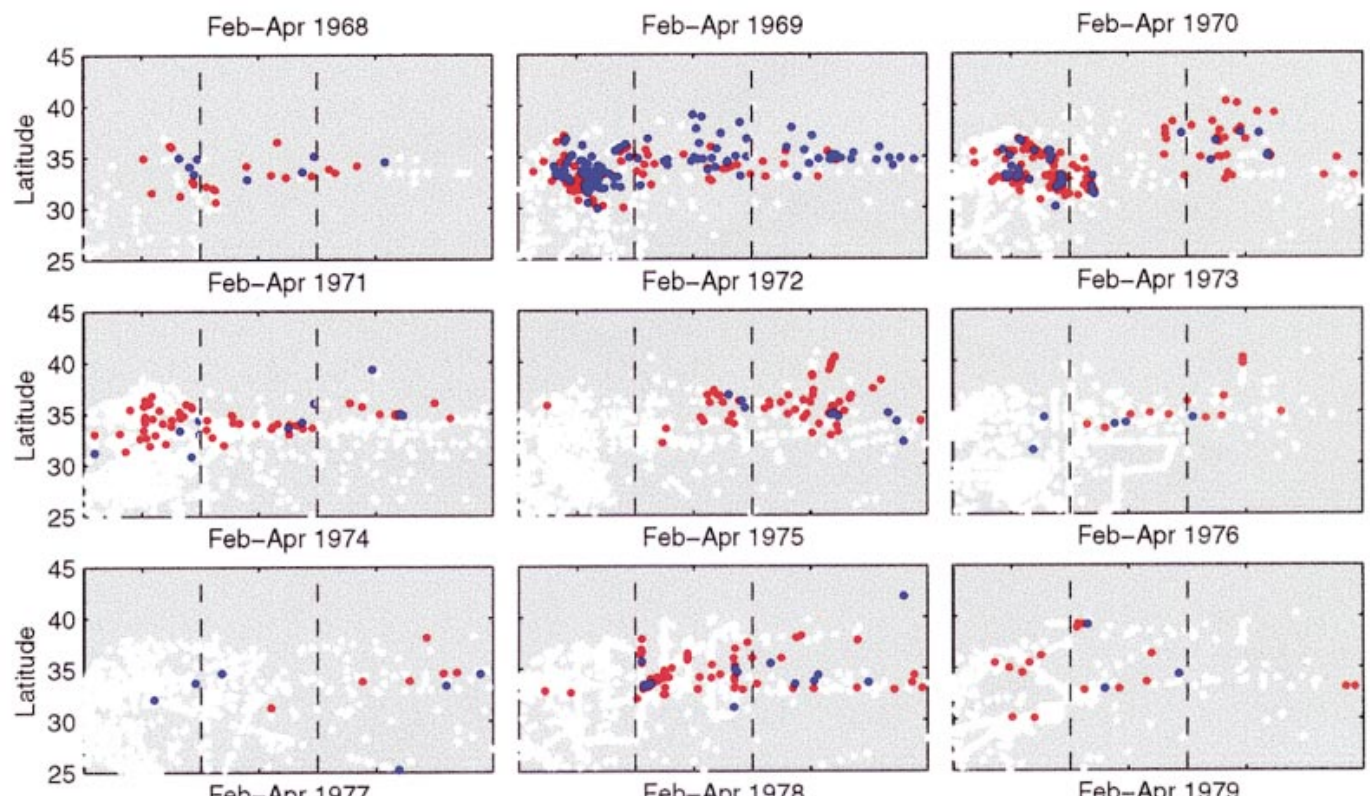

Feb-Apr 1976
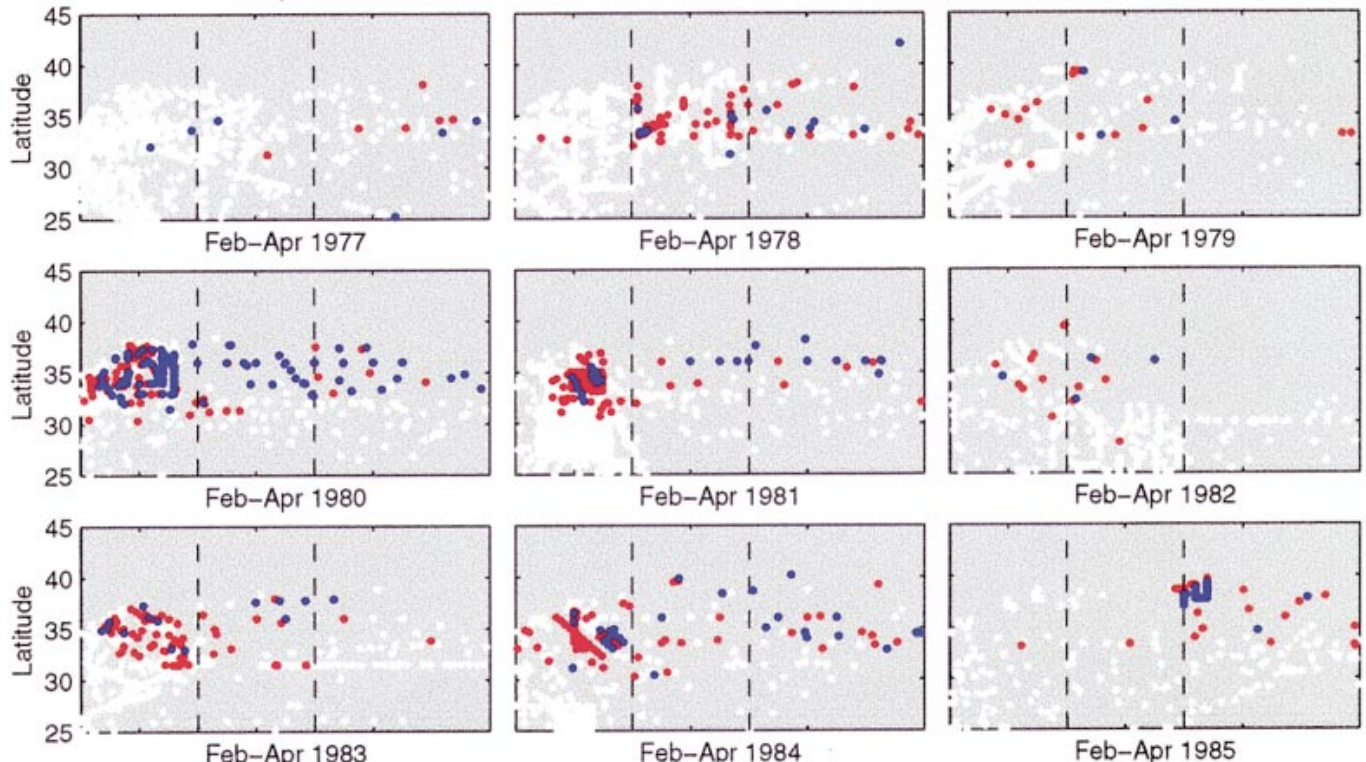

Feb-Apr 1979
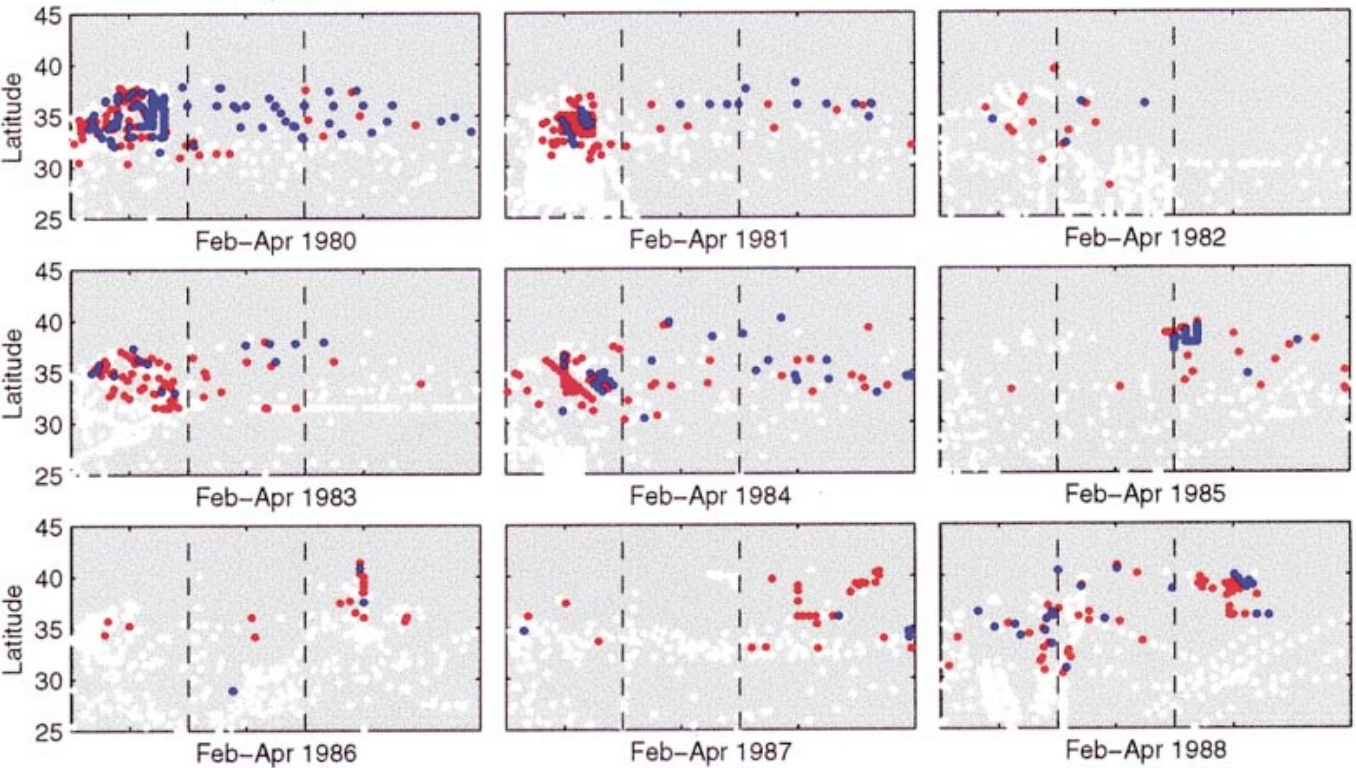

Feb-Apr 1982
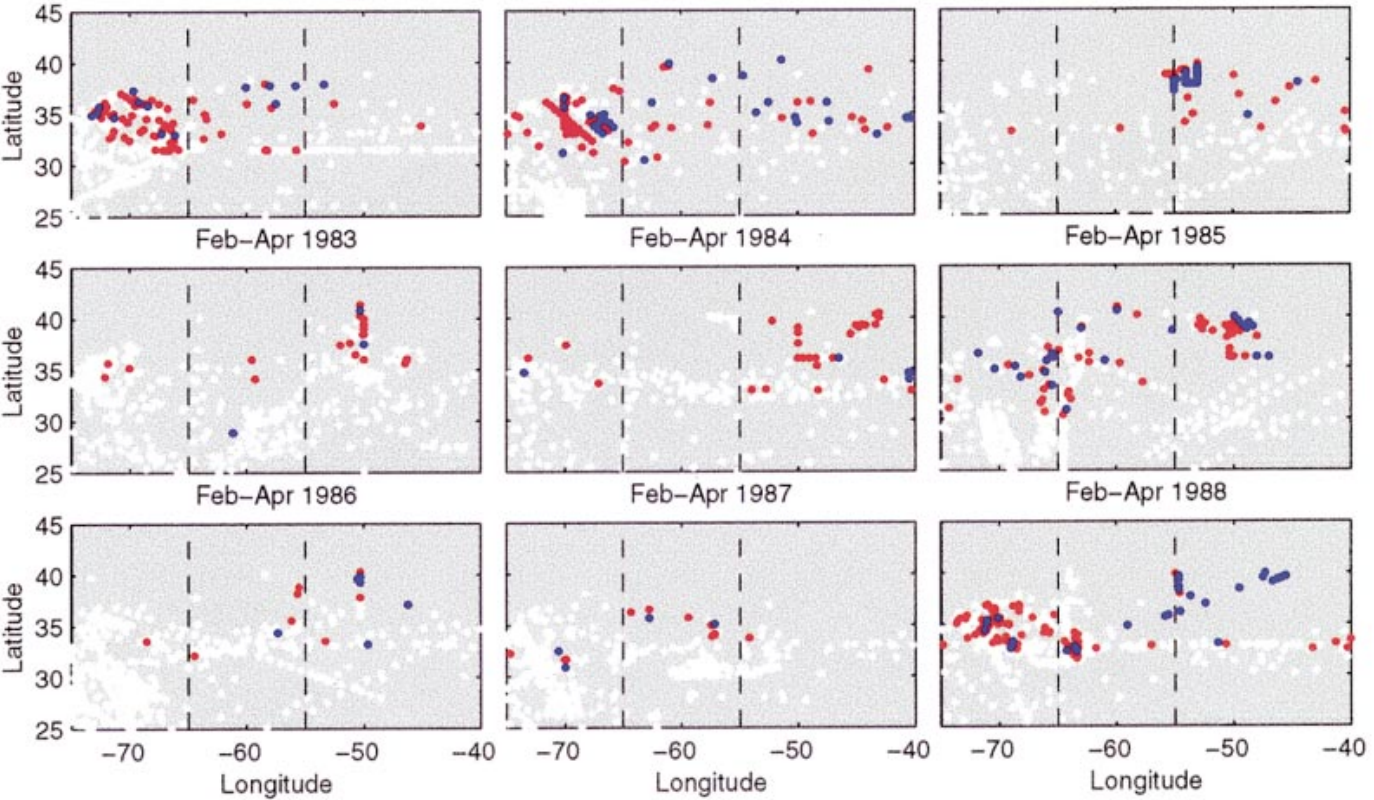

0

$0-0.5$

$>0.5$

FIG. 3. Feb-Apr profile positions. Symbol used to plot each profile position has been shaded to indicate the difference (in ${ }^{\circ} \mathrm{C}$ ) between the profile's mixed-layer temperature and temperature at top of the previous fall's STMW layer. See text for details. 

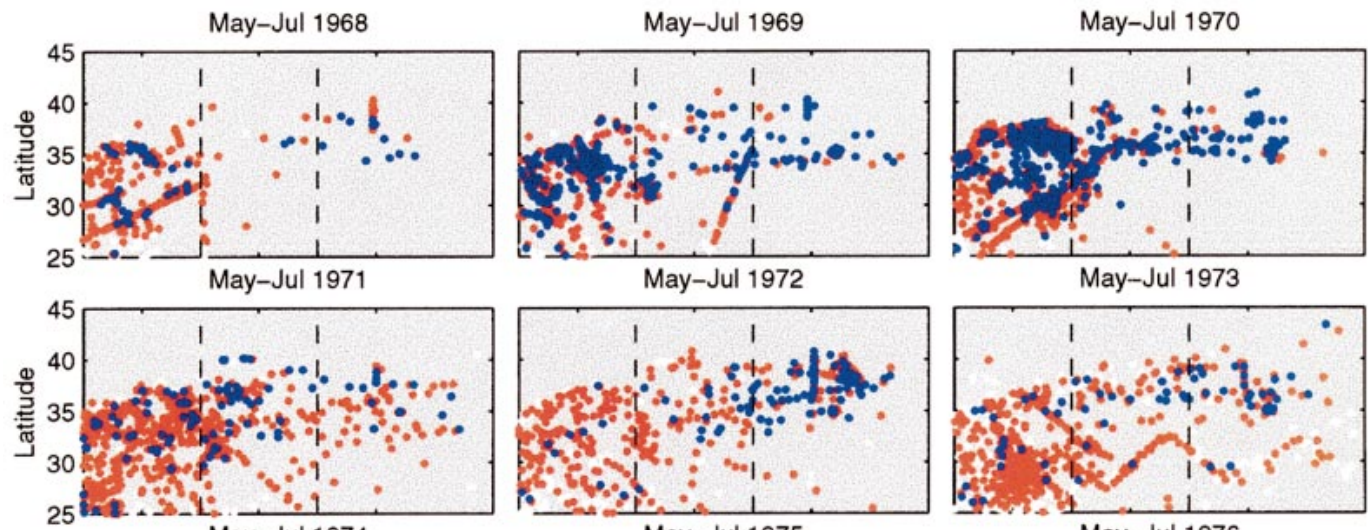

May-Jul 1973
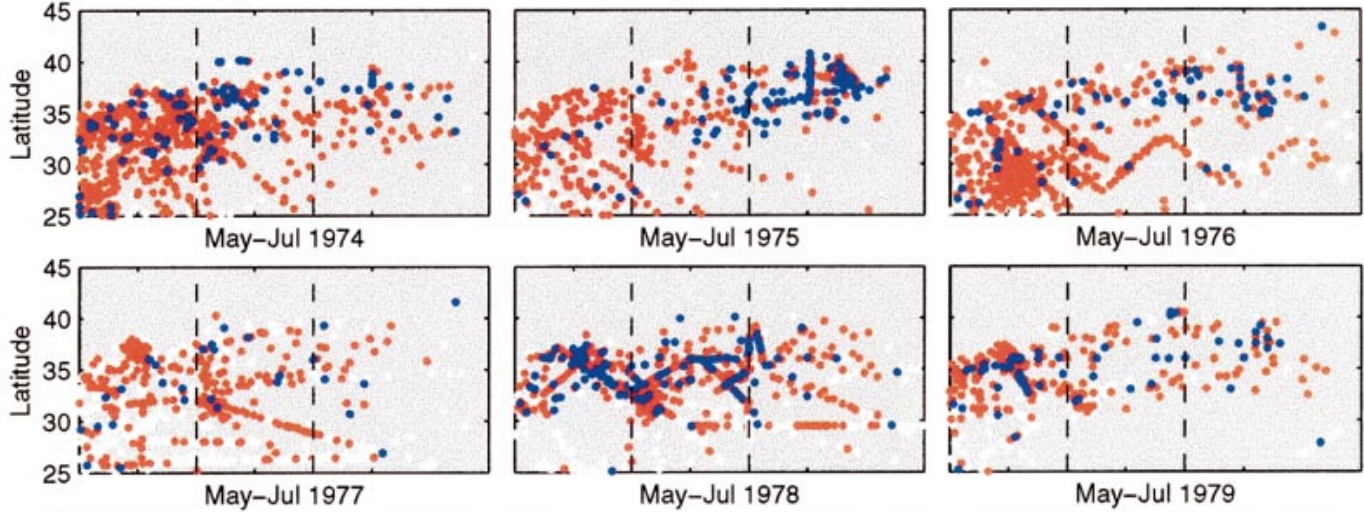

May-Jul 1976
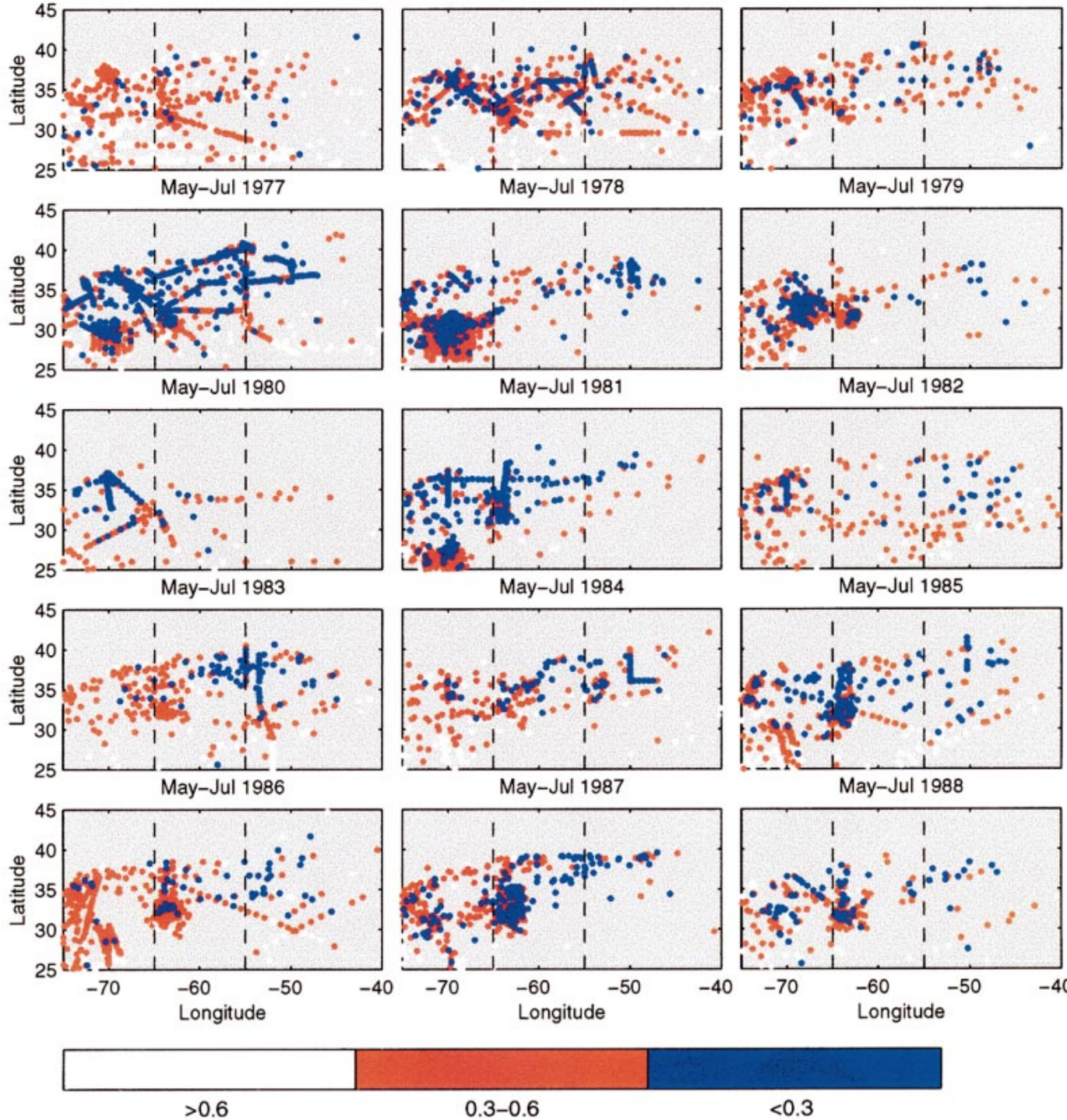

$0.3-0.6$

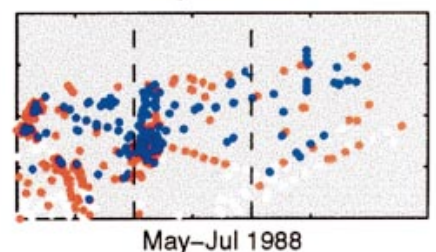

FIG. 4. May-Jul profile positions. Symbol used to plot each profile position has been shaded to indicate the mean temperature gradient (in ${ }^{\circ} \mathrm{C}$ per $100 \mathrm{~m}$ ) through the profile's STMW layer. See text for details. 
fall were determined for north and south of $30^{\circ} \mathrm{N}$ for the following three regions, $75^{\circ}-65^{\circ} \mathrm{W}, 65^{\circ}-55^{\circ} \mathrm{W}$, and $55^{\circ}-40^{\circ} \mathrm{W}$, indicated by dashed lines in Figs. $2-4$. These regions are large enough to allow for sufficient numbers of observations each year for a meaningful average while at the same time minimizing the east-west bias in the means. The $30^{\circ} \mathrm{N}$ delineation was chosen based on the changes in the STMW properties south of $30^{\circ} \mathrm{N}$ (Worthington 1959; Istoshin 1961; Alfultis and Cornillon 2001).

In Fig. 2, the winter mixed layer depths of profiles plotted in white were shallower than the top of the previous fall's STMW layer and therefore did not penetrate into the preexisting STMW layer. The winter mixed layers of profiles plotted in red penetrated less than 100 $\mathrm{m}$ into the previous fall's STMW layer, while those plotted in blue penetrated more than $100 \mathrm{~m}$ into the STMW layer. Similarly, profiles plotted in white in Fig. 3 had winter mixed layer temperatures that were warmer than the temperature at the top of the previous fall's STMW layer. Those profiles plotted with red had winter mixed layer temperatures up to $0.5^{\circ} \mathrm{C}$ colder than the temperature at the top of the preexisting STMW layer, while those plotted in blue were more than $0.5^{\circ} \mathrm{C}$ colder than the STMW layer top temperature. Finally, the color scale in Fig. 4 indicates the mean temperature gradient through the STMW layer. The STMW layers of profiles plotted in white were the most stratified, having temperature gradients greater than $0.6^{\circ} \mathrm{C}$ per $100 \mathrm{~m}$, while STMW layers of profiles plotted in blue were the most vertically homogeneous, having temperature gradients less than $0.3^{\circ} \mathrm{C}$ per $100 \mathrm{~m}$.

The data in the winter and spring of 1968 are sparse, but it appears from Figs. 2 and 3 that the winter mixed layer penetrated into the STMW layer, and there are several profiles the following spring with small temperature gradients (Fig. 4). Therefore, it appears that the STMW layer experienced some degree of convective mixing in 1968. The STMW layer underwent large-scale convective mixing and renewal of its vertical homogeneity in the 1969 and 1970 winters, as is evident from the large numbers of February-April profiles with cold, deep mixed layers and May-July profiles with small temperature gradients. The winters of 1971-74 show less convective mixing into the STMW layer than those of 1969 and 1970. While some of the mixed layers penetrated into the STMW layer during these winters, particularly to the east, all of these winters are characterized by warm February-April mixed layers relative to the STMW layer top temperature. The May-July temperature gradients also reflect the lack of renewal during these winters. Although there are a number of profiles with small temperature gradients in 1971 and to the east in 1972 and 1973, there are overall fewer profiles with small temperature gradients than in 1969 or 1970 . The number of profiles with small temperature gradients appears to decrease each year, reaching a minimum in 1974. Some of the winter mixed layers in 1975 and
1976 appear to penetrate into the STMW layer, but most of the mixed layers in these winters were warmer than the STMW top temperature. The number of profiles in spring with small temperature gradients also increased in 1975 and 1976 from 1971-74. Large-scale renewal of the STMW layer appears to return in the 1977 and 1978 winters with cold mixed layers penetrating into the STMW layer and a dramatically increased number of profiles in May-July with small temperature gradients. The 1979 winter data in the STMW formation region are sparse, especially east of $55^{\circ} \mathrm{W}$, but there are a number of profiles in the spring with small temperature gradients, indicating that some renewal of the STMW layer most likely occurred in 1979. While the 1980 and 1981 winters had some penetration into the STMW layer and some cold mixed layers, the rest of the 1980s appear to be characterized by little penetration and warm winter mixed layers. However, except for 1986, it is difficult to discern any appreciable change in the number of profiles in spring with small temperature gradients.

\section{a. Winter mixed layer characterizations}

To further assess the degree of STMW layer renewal each winter, time series of the temperature and depth at the top of the STMW layer each fall and the depth and temperature of winter mixed layers were constructed. Again, care must be taken in the averaging used to construct these time series due to the uneven data distribution. Therefore, the STMW formation region north of $30^{\circ} \mathrm{N}$ was again divided into the three regions $75^{\circ}-$ $65^{\circ} \mathrm{W}, 65^{\circ}-55^{\circ} \mathrm{W}$, and $55^{\circ}-40^{\circ} \mathrm{W}$.

The thin line in Fig. 5 is the mean depth of the deepest $25 \%$ of the February-April mixed layers from 1968 through 1988, while the heavy line depicts the mean depth of the top of the STMW layer in the previous fall (Nov 1967-Jan 1968 through Nov 1987-Jan 1988). Figure 6 shows the mean temperature of the coldest $25 \%$ of the February-April 1968-88 mixed layers (thin line) relative to the mean temperature at the top of the STMW layer in the previous (1967/68-1987/88) fall (heavy line). The mean depths and temperatures are the weighted means of clusters of profiles and remaining individual profiles, determined from Eq. (1). The error bars on each mean are the standard deviation of the weighted means found from Eq. (2).

From Figs. 5 and 6, the 1968-70 winters in all three regions are characterized by cold mixed layers penetrating the STMW layer. During these years of annual renewal of the STMW layer, the November-January mean temperature at the top of the STMW layer (Fig. 6 ) also decreased from one year to the next. The degree of renewal varied considerably from one region to the next and from one year to the next during the 1971-76 winters. West of $65^{\circ} \mathrm{W}$ in $1972-74$, the deepest winter mixed layers did not reach the top of the STMW layer and the coldest winter mixed layers were considerably warmer than the top of the STMW layer. In 1975 and 

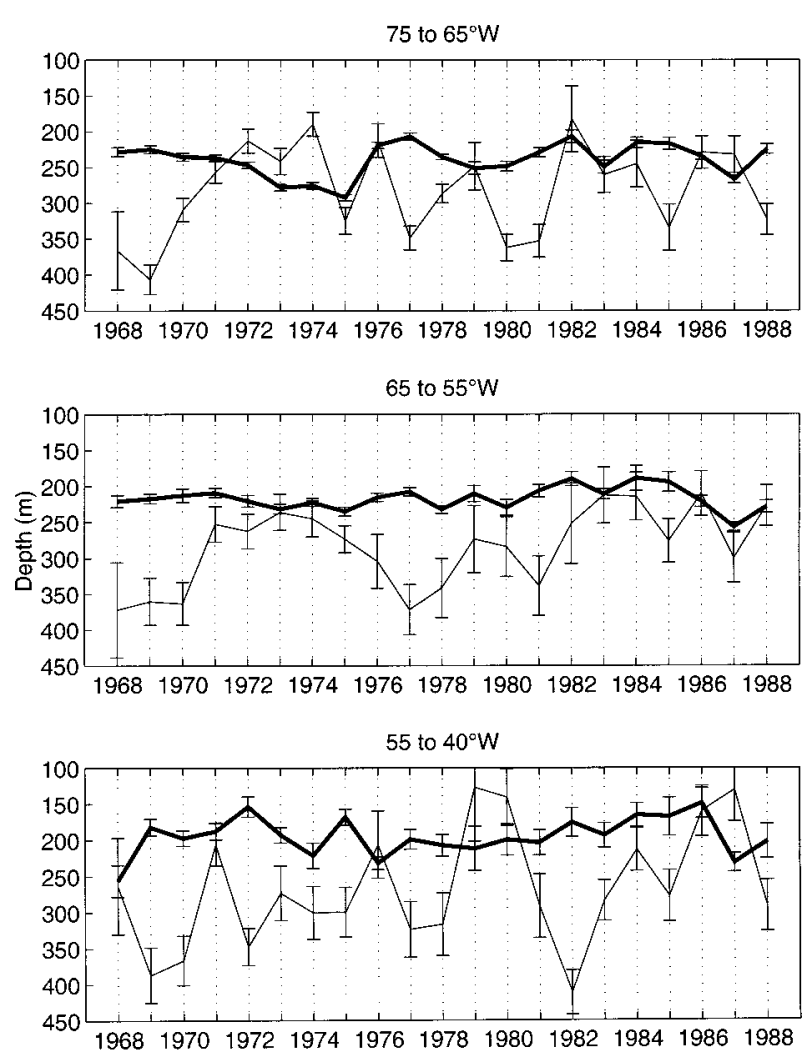

FIG. 5. Mixed layer and STMW top depth time series, 1968-88. The thin line represents the mean depth of the deepest $25 \%$ of the Feb-Apr mixed layers, while the heavy line represents the mean depth of the top of the Nov-Jan STMW layer. See text for details.

1976 in this region, the deepest winter mixed layers did reach the top of the STMW layer (Fig. 5), but the coldest winter mixed layers were still much warmer than the top of the STMW layer (Fig. 6). East of $55^{\circ} \mathrm{W}$, cold, deep winter mixed layers continued to penetrate into the STMW layer from 1972 to 1975 , with little or no penetration in 1971 and 1976 . The region $65^{\circ}-55^{\circ} \mathrm{W}$ is an intermediate case, with the deepest winter mixed layers reaching the top or slightly penetrating the top of the STMW layer in most winters but not to the degree found farther east. During these years of little or no renewal of the STMW layer (1971-76), the November-January mean temperature at the top of the STMW layer increased in all three regions. Widespread renewal of the STMW layer resumed in the 1977 and 1978 winters in all three regions, and the November-January mean temperature at the top of the STMW layer again decreased as it did following the 1969 and 1970 renewal events. The degree of STMW renewal varied considerably once again from 1980 through 1985. Cold winter mixed layers again penetrated into the STMW layer in 1980 and 1981 , except for east of $55^{\circ} \mathrm{W}$ in 1980 . West of $65^{\circ} \mathrm{W}$ in 1982,1983 , and 1984, the deepest winter mixed layers reached the top of the STMW layer, but the coldest mixed layers were considerably warmer than the STMW layer top temperature. East of $55^{\circ} \mathrm{W}$, however, cold
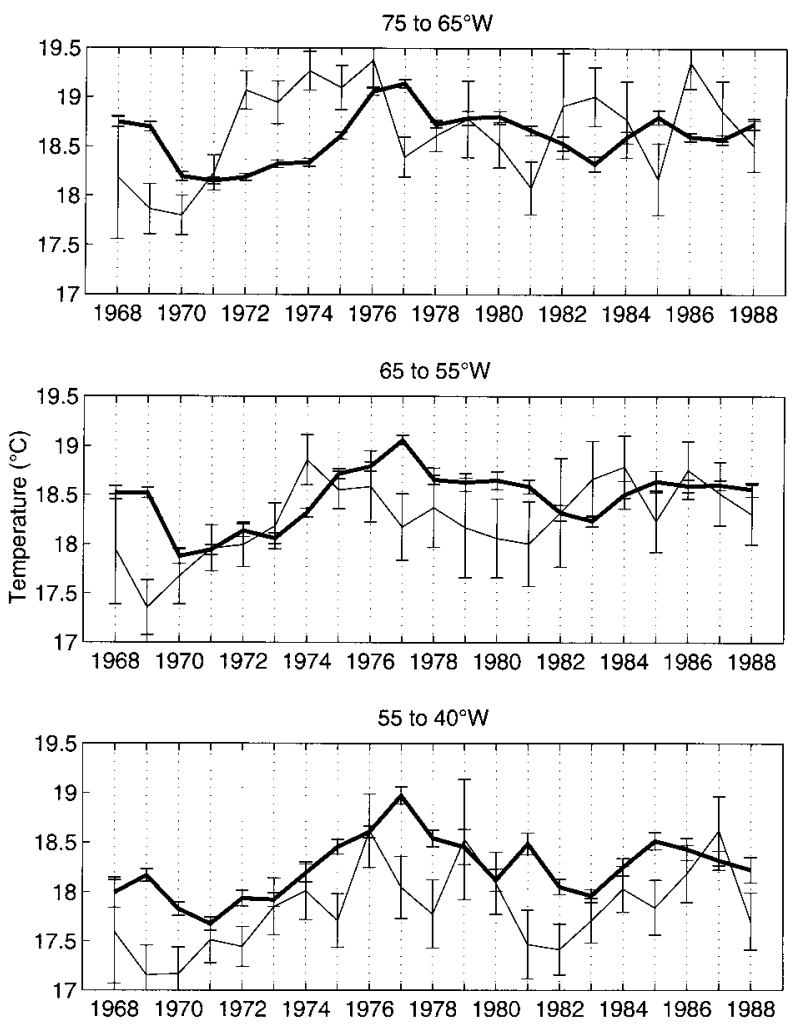

FIG. 6. Mixed-layer and STMW top temperature time series, 196888. The thin line represents the mean temperature of the coldest $25 \%$ of the Feb-Apr mixed layers, while the heavy line represents the mean temperature at the top of the Nov-Jan STMW layer. See text for details.

mixed layers continued to penetrate into the STMW layer during these winters. Widespread renewal of the STMW layer resumed in 1985 with deep, cold winter mixed layers existing in all three regions. There appears to have been little or no renewal of the STMW layer in 1986 or 1987 . The deepest winter mixed layers rarely penetrated the top of the STMW layer, and the coldest mixed layers were typically warmer than the STMW top temperature. Cold winter mixed layers again penetrated into the STMW layer in 1988 west of $65^{\circ} \mathrm{W}$ and east of $55^{\circ} \mathrm{W}$.

\section{b. STMW layer temperature gradient characterization}

The third characterization of STMW renewal involves comparing the mean temperature gradient through the STMW layer in fall, before it is exposed to direct atmospheric cooling, to the mean temperature gradient in late spring, after the return of the seasonal stratification has isolated the STMW layer from the atmosphere. The 3 -month mean temperature gradients for each year and the three regions north of $30^{\circ} \mathrm{N}$ are plotted in Fig. 7 . The first mean in each year is the May-July mean, followed by August-October and finally November-January. The February-April 3-month mean is not shown 

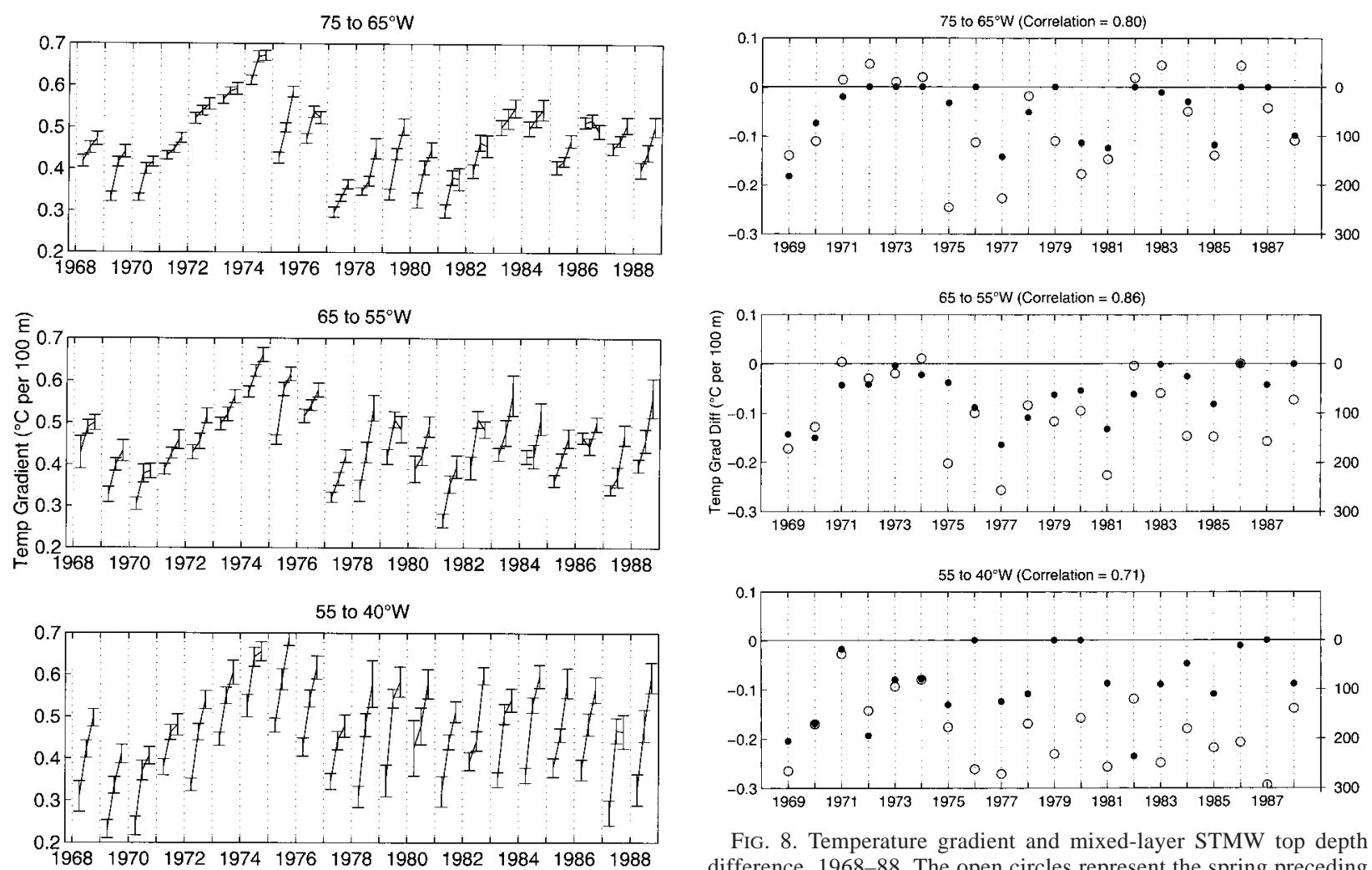

FIG. 8. Temperature gradient and mixed-layer STMW top depth difference, 1968-88. The open circles represent the spring preceding fall difference in the 3-month mean temperature gradients shown in Fig. 7. The dots represent the difference between the mixed-layer and STMW top depths shown in Fig. 5. Correlations between the two characterizations in each region are shown in parentheses.

since the STMW layer is generally still exposed to direct atmospheric forcing and in different stages of development (i.e., configurations 1-4) during these months. These 3-month means are the weighted means of clusters of profiles and remaining individual profiles using Eq. (1). The error bars on each mean are the standard deviation of the weighted means found using Eq. (2).

Since the temperature gradients in the spring (MayJul) of 1969 and 1970 were less than the previous fall (Nov-Jan) in all three regions, there appears to have been widespread convective mixing and a thickening/ homogenizing of the STMW layer during these two winters, in agreement with the mixed layer characterization. The temperature gradients west of $65^{\circ} \mathrm{W}$ consistently increased from 1971 through 1974, indicating no renewal of the STMW layer in this region during these years. East of $55^{\circ} \mathrm{W}$, however, STMW renewal appears to have continued during these winters. The temperature gradients decreased from fall to spring in all three regions from 1975 through 1981 . West of $55^{\circ} \mathrm{W}$, the temperature gradients increased from fall to spring in 1982, 1983, and 1986, while they decreased during each of these springs east of $55^{\circ} \mathrm{W}$.

\section{c. Comparison of characterizations}

The results from the characterizations seem to be in general agreement. They show large-scale renewal of

the STMW layer in 1969, 1970, 1977, 1978, and 1985; no renewal west of $65^{\circ} \mathrm{W}$ from 1971 to 1974 ; and renewal occurring more often east of $55^{\circ} \mathrm{W}$ than west of $65^{\circ} \mathrm{W}$. To assess the agreement of these characterizations more carefully, two time series combining the different characterizations were constructed. In the first time series (Fig. 8), the difference between the May-July and the preceding November-January (spring minus preceding fall) mean temperature gradients is plotted with the depth difference between the mean November-January STMW layer top and the mean depth of the deepest $25 \%$ of the February-April mixed layers. The difference in the spring and preceding fall mean temperature gradients is again plotted in the second time series (Fig. 9) but now with the temperature difference between the mean November-January STMW top and the mean of the coldest $25 \%$ of the February-April mixed layers. This temperature difference has been converted to a depth difference using the mean November-January temperature gradient through the STMW layer. In both of these figures, the summer-fall temperature gradient differences are plotted with open circles. The solid line in each figure represents no change in the 3-month mean temperature gradient. Points above this line represent those temperature gradients that increased from fall to the following spring, while those below the line rep- 

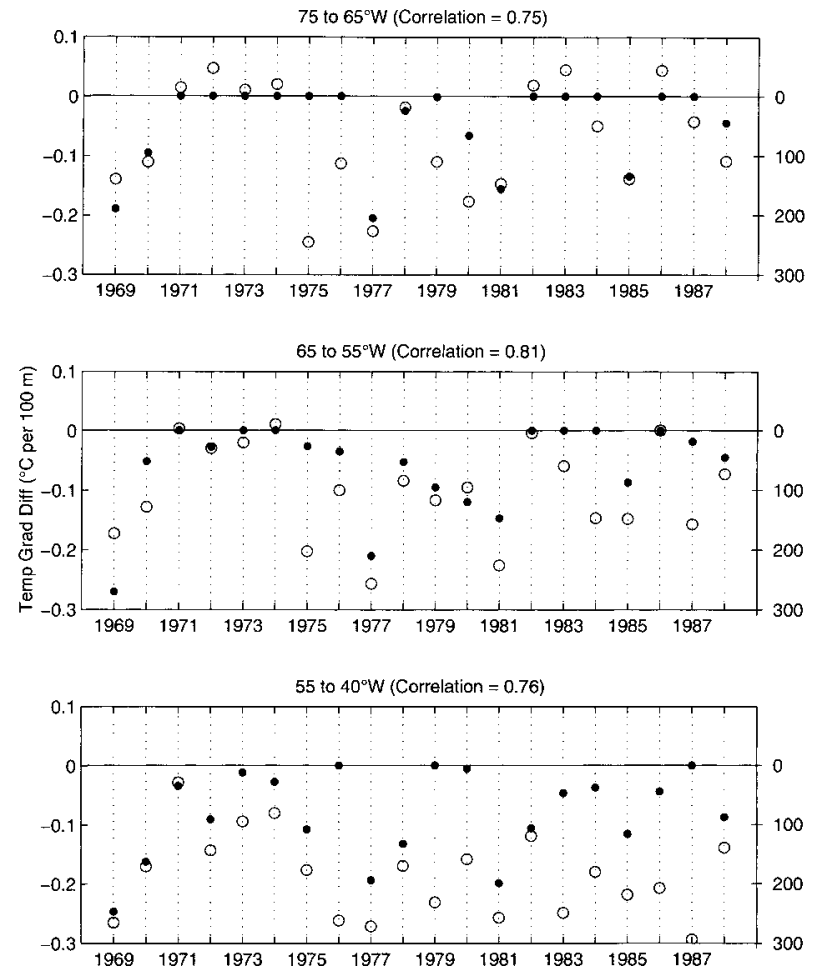

FIG. 9. Temperature gradient and mixed-layer STMW top temperature difference, 1968-88. The open circles represent the spring preceding fall difference in the 3 -month mean temperature gradients shown in Fig. 7. The dots represent the difference between the mixedlayer and STMW top temperatures shown in Fig. 6. Correlations between the two characterizations in each region are shown in parentheses.

resent temperature gradients in spring that were less than the previous fall. In both figures, the mixed layer STMW layer differences are plotted using solid dots, with their corresponding axis to the right. Years when the mixed layer was shallower or warmer than the top of the STMW layer were set to zero and are plotted along the solid line.

These figures show good agreement between the three different characterizations. Generally, when the winter mixed layers penetrated into the STMW layer more than $50 \mathrm{~m}$ (Fig. 8), the temperature gradients through the STMW layer were smaller in spring than they were in the previous fall. The correlation coefficients between the mixed layer and temperature gradient characterizations for each region are shown in Figs. 8 and 9. The mixed layer and temperature gradient characterizations are significantly correlated at the $95 \%$ confidence level, whether comparing the STMW temperature gradients to mixed layer depths or temperatures converted to depths.

There are some exceptions, however. Large decreases in the temperature gradient with little corresponding winter penetration into the STMW layer occurred in 1975,1976 , and 1979 west of $65^{\circ} \mathrm{W} ; 1975,1984$, and 1987 from $65^{\circ}$ to $55^{\circ} \mathrm{W}$; and $1976,1979,1980,1986$, and 1987 east of $55^{\circ} \mathrm{W}$. In addition, the winter mixed layers penetrated more than $50 \mathrm{~m}$ into the STMW layer, but the temperature gradients through the STMW layer were not reduced in the springs of 1978 west of $65^{\circ} \mathrm{W}$ and 1982 in the $65^{\circ}-55^{\circ} \mathrm{W}$ region.

There are several possible reasons for the discrepancies between the three characterizations. First, the data sampling in February through April could have been such that the periods/locations with the deepest mixed layers were missed or undersampled. This may have been the case in 1982 and 1987 in the $65^{\circ}-55^{\circ} \mathrm{W}$ region and in 1976, 1979, and 1987 east of $55^{\circ} \mathrm{W}$. The month of March in particular was undersampled in these regions/years and in some, two of the three late winter months (Feb through Apr, when the mixed layers would be their deepest) were undersampled (Alfultis 1997). Poor sampling, then, may explain why the two characterizations do not agree in 5 of the 14 cases.

Another possible explanation is that profiles with small temperature gradients were formed to the west in winter and advected into the regions the following spring, resulting in reduced temperature gradients in spring without substantial penetration in the winter. This argument cannot be applied to the westernmost region but could explain the differences in the other two regions. However, for the years where the two characterizations do not agree in the $65^{\circ}-55^{\circ} \mathrm{W}$ region, there was penetration into the STMW layer west of $65^{\circ} \mathrm{W}$ only in 1975. In fact, in 1984 and 1987 both characterizations showed no renewal of the STMW layer west of $65^{\circ} \mathrm{W}$, and yet the temperature gradients were reduced from fall to spring in the $65^{\circ}-55^{\circ} \mathrm{W}$ region in these years. Advection can be ruled out west of $55^{\circ} \mathrm{W}$ in 1976,1980 , 1986, and 1987 as well. In each of these years, either the characterizations showed no renewal to the west (1986 and 1987) or the STMW layer in this region was too cold to have been advected from the west (1976 and 1980). Therefore, advection is a possible explanation for the large decrease in temperature gradient in 1975 in the $65^{\circ}-55^{\circ} \mathrm{W}$ region and 1979 in the $55^{\circ}-40^{\circ} \mathrm{W}$ region.

The characterizations also would not agree if the spring STMW layer was thicker than the previous fall STMW layer, but no convective mixing (i.e., no deep, cold mixed layers) occurred in the winter. This could occur in those years when the mixed layers are deep enough to reach the top or even penetrate into the STMW by less than $50 \mathrm{~m}$, but the mixed layer temperatures are warmer than the temperatures previously at the top of the STMW layer. In this case, a thin, warm STMW layer could form on the upper part of the older, preexisting STMW layer. Although this dual STMW layer will have a relatively large change in temperature from top to bottom and little renewal of the preexisting STMW layer, its large thickness will result in a reduced temperature gradient. The method used here to identify the STMW layer would identify the two STMW layers as a single, thick STMW layer because it could not distinguish the newly formed STMW layer from the 
preexisting STMW layer due the small differences in the temperature and temperature gradient of each layer (Alfultis and Cornillon 2001).

The formation of these thick, dual-layer STMW layers is a possible explanation for the discrepancies between the characterizations in 1975 in both of the westernmost regions and in 1976 and 1979 west of $65^{\circ} \mathrm{W}$. In these years, warm mixed layers did reach and slightly penetrate the top of the STMW layer. For example, in 1975 , the mean depth of the deepest $25 \%$ of the mixed layers west of $65^{\circ} \mathrm{W}$ was $360 \mathrm{~m}, 70 \mathrm{~m}$ deeper than the top of the STMW layer in the previous fall, but the mean of the coldest $25 \%$ of the mixed layers was $0.4^{\circ} \mathrm{C}$ warmer than the temperature at the top of the STMW layer. Also, the temperature at the top of the STMW layer warmed by $0.5^{\circ} \mathrm{C}$ from fall to spring in 1975 . In these dual-layer STMW layer cases, the rms difference between the best-fit line through the STMW layer (consisting of both the new and old layer) would be large. The mean rms difference was largest in 1975, 1976, and 1979 west of $65^{\circ} \mathrm{W}$ and in 1975 and 1984 in the $65^{\circ}$ $55^{\circ} \mathrm{W}$ region.

Forming a new STMW layer near the top of a preexisting one is not the only explanation for thick STMW layers with large rms, however. STMW layers containing temperature inversions or noise would also have a large rms and could be thick. Therefore, although the results from 1975, 1976, and 1979 point to a plausible geophysical explanation for the discrepancies between the two methods, it is difficult to establish the relative importance of the formation of multiple-layer STMW layers to random errors creating thick STMW layers without penetration of winter mixed layers.

\section{d. Comparison with other observations of STMW renewal}

The observations of STMW renewal by Talley and Raymer (1982), Jenkins (1982), Cornillon et al. (1987), and Klein and Hogg (1996) coincide at various times with these time series of STMW renewal (Figs. 5-7) and therefore can be compared with these results. Talley and Raymer (1982) and Jenkins (1982) used the Panulirus hydrographic station data to estimate the degree of large-scale renewal of the subtropical gyre. Talley and Raymer (1982) examined variations in STMW properties at the potential vorticity (potential density gradient) minimum from 1954 to 1978 . They found that the STMW arriving at Bermuda in 1969-71 had been renewed each year and that the temperatures at the potential vorticity minimum became progressively colder each year. Both of these trends are seen here as well (Figs. 5-6). They argued that the STMW arriving at Bermuda from 1972 to 1975 was not renewed and they found the temperatures at the potential vorticity minimum increased. This agrees with the observations seen here west of $55^{\circ} \mathrm{W}$. STMW formed east of $55^{\circ} \mathrm{W}$ in these years would either have been advected south of Ber- muda by the subtropical gyre recirculation or to the east and never incorporated into the subtropical gyre, as was observed by Klein and Hogg (1996) in 1988. Talley and Raymer (1982) found newly formed STMW formation arriving at Bermuda again in 1975 or 1976, but the temperatures and densities of this STMW were anomalously warm and low, respectively. This agrees with the warm, thick dual-layer STMW layers observed here in these years. They found the STMW arriving at Bermuda in 1977 and 1978 had recently been renewed, and the temperatures at the potential vorticity minimum decreased in these years as well, in agreement with the results shown in Figs. 5-6.

Jenkins (1982) characterized the degree of renewal of the subtropical gyre using salinity on isopycnals, radioactive tracers, and oxygen data, all at the Panulirus hydrographic station near Bermuda. He argued that increased salinity on isopycnals is indicative of a high latent heat flux in winter and therefore ventilation. From oxygen, salinity, and radioactive tracer data, he also estimated the water mass renewal rate on isopycnals. From these data, he found high salinities on isopycnals in 1969 and 1970, indicating large-scale renewal of the subtropical gyre in these winters; decreasing salinities and water mass renewal rates on isopycnals from 19691976, indicating less large-scale renewal in these years; increasing salinities and water mass renewal rates on isopycnals from 1976 to 1980; and from radioactive tracer data alone, there was less ventilation of the subtropical gyre in 1974 and 1975 than in 1977 and 1978. Although it is difficult to compare the Jenkins (1982) conclusions based on data at a single point to all three regions used here, there is good general agreement between his results and those found here, that is, largescale renewal in 1969 and 1970, no renewal in 19711976, and increased renewal in 1977 through 1980.

Cornillon et al. (1987) used satellite observations to construct sea surface temperature time series in $215 \mathrm{~km}$ $\times 215 \mathrm{~km}$ squares for January through May 1983. Based on their results, it appears that convective mixing and renewal occurred in a limited region of the subtropical gyre in 1983 , that is, east of $63^{\circ} \mathrm{W}$ and north of $32.5^{\circ} \mathrm{N}$. The characterizations of STMW renewal used here also found renewal in the eastern portion of the subtropical gyre with no renewal to the west in 1983 (Figs. 5-7).

Based on their coupled isopycnal-mixed layer model, Hazeleger and Drijfhout (1998) found that STMW formation began in the northeastern portion of the subtropical gyre due to the seasonal north-south shifting of the mixed layer isotherms (outcrops). This northsouth shifting of the outcrops exposes the STMW layer to atmospheric cooling and convective mixing in winter and caps the STMW layer with a seasonal mixed layer in summer. They also found that advection of warm water along the western portion of the subtropical gyre limits this north-south shifting of isotherms, thus limiting exposure of the STMW layer in this portion of the gyre to atmospheric cooling and convective renewal. 
These numerical model results are in agreement with our observations that the STMW layer is renewed more often in the eastern portion of the subtropical gyre than the western portion.

Finally, Klein and Hogg (1996) used current meter data near $55^{\circ} \mathrm{W}$, Panulirus hydrographic data, and XBT data to examine STMW formation in 1987, 1988, and 1989. They found warm STMW $\left(>17.8^{\circ} \mathrm{C}\right)$ formed between $65^{\circ}$ and $57^{\circ} \mathrm{W}$ and no formation west of $65^{\circ} \mathrm{W}$ or east of $57^{\circ} \mathrm{W}$ in 1987 , warm STMW $\left(>18.1^{\circ} \mathrm{C}\right)$ formed west of $63^{\circ} \mathrm{W}$ and cold STMW $\left(\sim 17.6^{\circ} \mathrm{C}\right)$ formed east of $59^{\circ} \mathrm{W}$ in 1988 . They concluded that the cold STMW east of $59^{\circ} \mathrm{W}$ in 1988 was advected east, out of the subtropical gyre, and was therefore not incorporated into the gyre. The formation of warm STMW layers from $65^{\circ}$ to $57^{\circ} \mathrm{W}$ in 1987 agrees with Figs. 5-6, which showed warm mixed layers penetrating to the top of the STMW layer in winter in the $65^{\circ}-55^{\circ} \mathrm{W}$ region and reduced temperature gradients in spring, that is, formation of a warm, thick dual-layer STMW layer. Figure 5 shows that the winter mixed layers do not penetrate to the top of the STMW layer west of $65^{\circ} \mathrm{W}$ or east of $55^{\circ} \mathrm{W}$ in 1987. Therefore, there was no STMW formation/renewal in these two regions, which agrees with the Klein and Hogg (1996) results. These figures also show penetration of cold mixed layers into the STMW layer west of $65^{\circ} \mathrm{W}$ and east of $55^{\circ} \mathrm{W}$ in 1988 and less penetration in the $65^{\circ}-55^{\circ} \mathrm{W}$ region, again in agreement with Klein and Hogg (1996).

The presence of these dual-layer STMW layers has two implications. First, since it appears STMW can be formed without renewing the preexisting STMW layer, a distinction should be made between STMW formation and renewal of the STMW layer. Second, it appears more care may be needed in defining the STMW layer "core." Several authors (McCartney 1982; Talley and Raymer 1982; Ebbesmeyer and Lindstrom 1986; Klein and Hogg 1996) have defined the STMW layer core as the potential vorticity minimum. In cases where there is a shallow STMW layer formed on top of a preexisting STMW layer, the potential vorticity minimum will be located in the more recently formed, but shallow, STMW layer. For example, the Talley and Raymer (1982) potential vorticity characterization indicated that newly formed STMW arrived at Bermuda in 1975 but it was a warmer and less dense variety of STMW. Based on these results, it appears that this newly formed STMW was the remnant of the warm mixed layers that penetrated to the top of the STMW layer but did not entirely renew the preexisting STMW layer. Deepening of the seasonal pycnocline will result in reentrainment of waters from this layer back into the mixed layer. This will significantly reduce the thickness of this layer, and the shallower STMW layer could possibly be totally reentrained back into the mixed layer. Thus, defining the core of the STMW layer in this way may not be suitable for following changes in the STMW layer over time. It may be more appropriate to either treat the
TABLE 1. 1969-88 STMW renewal events. R: renewal event; NR: no renewal; ?: characterizations do not agree.

\begin{tabular}{cccc}
\hline \hline Years & $75^{\circ}-65^{\circ} \mathrm{W}$ & $65^{\circ}-55^{\circ} \mathrm{W}$ & $55^{\circ}-40^{\circ} \mathrm{W}$ \\
\hline 1969 & $\mathrm{R}$ & $\mathrm{R}$ & $\mathrm{R}$ \\
1970 & $\mathrm{R}$ & $\mathrm{R}$ & $\mathrm{R}$ \\
1971 & $\mathrm{NR}$ & $\mathrm{NR}$ & $\mathrm{NR}$ \\
1972 & $\mathrm{NR}$ & $\mathrm{NR}$ & $\mathrm{R}$ \\
1973 & $\mathrm{NR}$ & $\mathrm{NR}$ & $\mathrm{R}$ \\
1974 & $\mathrm{NR}$ & $\mathrm{NR}$ & $\mathrm{R}$ \\
1975 & $?$ & $?$ & $\mathrm{R}$ \\
1976 & $?$ & $\mathrm{R}$ & $?$ \\
1977 & $\mathrm{R}$ & $\mathrm{R}$ & $\mathrm{R}$ \\
1978 & $?$ & $\mathrm{R}$ & $\mathrm{R}$ \\
1979 & $?$ & $\mathrm{R}$ & $?$ \\
1980 & $\mathrm{R}$ & $\mathrm{R}$ & $?$ \\
1981 & $\mathrm{R}$ & $\mathrm{R}$ & $\mathrm{R}$ \\
1982 & $\mathrm{NR}$ & $?$ & $\mathrm{R}$ \\
1983 & $\mathrm{NR}$ & $\mathrm{NR}$ & $\mathrm{R}$ \\
1984 & $\mathrm{NR}$ & $?$ & $\mathrm{R}$ \\
1985 & $\mathrm{R}$ & $\mathrm{R}$ & $\mathrm{R}$ \\
1986 & $\mathrm{NR}$ & $\mathrm{NR}$ & $?$ \\
1987 & $\mathrm{NR}$ & $?$ & $?$ \\
1988 & $\mathrm{R}$ & $?$ & $\mathrm{R}$ \\
\hline
\end{tabular}

STMW layer as a layer rather than a single point in the layer or to identify the core of the STMW layer as the potential vorticity minimum when the seasonal pycnocline is at its maximum depth.

Here, STMW renewal events will be identified by the penetration of cold mixed layers more than $50 \mathrm{~m}$ into the STMW layer and a decrease in the mean temperature gradient from fall to spring. Table 1 identifies the years meeting these criteria as years of STMW renewal, those years where these criteria were not satisfied as no STMW renewal, and those years where the characterizations were not consistent.

\section{Annual changes in the STMW layer}

Perhaps the most striking features of Fig. 7 are the annual and interannual changes in the temperature gradient through the STMW layer. In winters when the STMW layer was renewed (1969, 1970, 1977, 1978, 1981, and 1985), the temperature gradient increased at a relatively constant rate through the rest of the year in each of the three regions. Looking at the change in the temperature gradient from 1970 through 1974 in the two westernmost regions where there was no STMW renewal, the temperature gradient continued to increase from one year to the next but at a smaller rate than during the years of STMW renewal. The increase in the temperature gradient with time following renewal of the STMW layer will be defined here as the "erosion" of the thermostad and the "restratification rate" as the rate at which the temperature gradient increases. In this section, the annual restratification rate is first estimated from the changes in each year's three 3-monthly mean temperature gradients in Fig. 7. The processes that can increase the STMW layer's temperature gradient following each winter are also discussed. In the next sec- 
TABLE 2. Annual mean changes in temperature gradient from mean slopes of best-fit lines to Fig. 7.

\begin{tabular}{lcc}
\hline \hline & Mean & $\begin{array}{c}\text { Standard error } \\
\text { of the mean } \\
(\sigma / \sqrt{n})\end{array}$ \\
\hline $75^{\circ}-65^{\circ} \mathrm{W}$ & All years $\left({ }^{\circ} \mathrm{C}\right.$ per $100 \mathrm{~m}$ per day) \\
$65^{\circ}-55^{\circ} \mathrm{W}$ & $3.9 \times 10^{-4}$ & $0.5 \times 10^{-4}$ \\
$55^{\circ}-40^{\circ} \mathrm{W}$ & $5.5 \times 10^{-4}$ & $0.5 \times 10^{-4}$ \\
& $10.3 \times 10^{-4}$ & $0.5 \times 10^{-4}$ \\
$75^{\circ}-65^{\circ} \mathrm{W}$ & Renewal years $\left({ }^{\circ} \mathrm{C} \mathrm{per} 100 \mathrm{~m}\right.$ per day $)$ \\
$65^{\circ}-55^{\circ} \mathrm{W}$ & $4.7 \times 10^{-4}$ & $0.5 \times 10^{-4}$ \\
$55^{\circ}-40^{\circ} \mathrm{W}$ & $6.0 \times 10^{-4}$ & $0.8 \times 10^{-4}$ \\
& $10.9 \times 10^{-4}$ & $0.6 \times 10^{-4}$ \\
$75^{\circ}-65^{\circ} \mathrm{W}$ & Nonrenewal years $\left({ }^{\circ} \mathrm{C}\right.$ per 100 m per day $)$ \\
$65^{\circ}-55^{\circ} \mathrm{W}$ & $2.4 \times 10^{-4}$ & $0.5 \times 10^{-4}$ \\
\hline
\end{tabular}

tion, the interannual restratification rate is estimated by examining the changes in the temperature gradient from the time at which the STMW layer was last renewed.

To examine the changes in the temperature gradient through the year, the annual 3-month mean temperature gradients in Fig. 7 were averaged to form one mean for each 3-month period. In this averaging, each year's 3month mean temperature gradient was weighted by its standard deviation, and the mean was again found using Eq. (1). The standard error of the mean was found using Eq. (2). Finding the means in this way ensures that each year has nearly the same weight and prevents the means from being biased toward those years with large numbers of profiles.

The 3-month mean temperature gradients for years when the STMW layer was renewed by convective mixing were determined separately from years when the STMW layer experienced no convective mixing. The years of STMW renewal were chosen as 1969, 1970, 1977, 1980, 1981, and 1985. The years with no STMW renewal were chosen as 1971, 1972, 1973, 1974, 1982, 1983, and 1986. These were the years when the two criteria discussed in sections $3 \mathrm{a}$ and $3 \mathrm{~b}$ were consistent in their assessment of either renewal or no renewal in the two westernmost regions (west of $55^{\circ} \mathrm{W}$ ). Since the two criteria indicate STMW renewal almost every year east of $55^{\circ} \mathrm{W}$, the easternmost region was not considered in classifying a year as one of STMW renewal or no renewal.

For the two westernmost regions Fig. 7 suggests the annual restratification rate is larger (i.e., the temperature gradient is increasing faster) during renewal years than nonrenewal years. In order to quantify the restratification rate and the differences in this rate in renewal and nonrenewal years, the slope of the least squares best-fit line to each year's three 3-month mean temperature gradients was found. Table 2 lists the mean and standard errors of these annual slopes for all years, renewal years, and (for the two westernmost regions) nonrenewal years for each region. From this table, two trends stand out.
TABLE 3. Interannual mean changes in temperature gradient, thickness, and temperature difference.

\begin{tabular}{|c|c|}
\hline & $75^{\circ}-65^{\circ} \mathrm{W}$ \\
\hline Temperature gradient & $1.9 \times 10^{-4{ }^{\circ} \mathrm{C}}$ per $100 \mathrm{~m}$ per day \\
\hline Thickness & $-3.3 \times 10^{-2} \mathrm{~m}$ per day \\
\hline Temperature difference & $+2.2 \times 10^{-4^{\circ} \mathrm{C} \text { per day }}$ \\
\hline & $65^{\circ}-55^{\circ} \mathrm{W}$ \\
\hline Temperature gradient & $1.8 \times 10^{-4{ }^{\circ}} \mathrm{C}$ per $100 \mathrm{~m}$ per day \\
\hline Thickness & $-2.5 \times 10^{-2} \mathrm{~m}$ per day \\
\hline Temperature difference & $+2.3 \times 10^{-4^{\circ} \mathrm{C} \text { per day }}$ \\
\hline
\end{tabular}

First, the annual restratification rates increase from west to east. Second, the rates are statistically larger for renewal years than for nonrenewal years.

In order to examine some of the processes responsible for the increase in the STMW layer's temperature gradient through the year, the changes in the STMW layer's top and bottom temperature and depth, and their differences, were examined. Three-month averages of depth and temperature of the STMW layer top and bottom along with the STMW layer thickness and temperature change through the layer were calculated by again first finding the average of each year, then the mean of all years using Eq. (1), and the standard error of the means was found using Eq. (2).

With one exception, the changes in thickness in the renewal years are similar to those in the nonrenewal years. Except for the renewal years in the $65^{\circ}-55^{\circ} \mathrm{W}$ region, the thickness decreases by $\sim 20-30 \mathrm{~m}$ from May-July to August-October, then by $\sim 10-15 \mathrm{~m}$ from August-October to November-January (Alfultis 1997). These later changes in thickness are similar to those found by Suga et al. (1989) in the North Pacific. They found the North Pacific STMW layer thinned on average by $15 \mathrm{~m}$ from late summer (6 months after formation) to late winter (12 months after formation). The temperature difference through the STMW layer increases only slightly through the course of the year in renewal years, while it decreases (west of $65^{\circ} \mathrm{W}$ ) or remains nearly constant (east of $65^{\circ} \mathrm{W}$ ) in nonrenewal years (Alfultis 1997). Thus, the annual restratification rate following winters of STMW renewal seems to be primarily due to annual decreases in thickness. Hazeleger and Drijfhout (1998) also found, using an isopycnal model of the North Atlantic subtropical gyre coupled with a mixed layer model, that the potential vorticity of STMW formed in the central portion of the STMW increases after formation mainly due to the STMW thinning as the seasonal pycnocline develops and deepens. In addition, the slight annual increase in the temperature difference through the layer following renewal years acts in concert with the seasonal thinning of the STMW layer to increase the temperature gradient, whereas the annual decrease in the temperature difference through the layer in the nonrenewal years acts to decrease the temperature gradient, opposite to the thinning of the STMW layer. Thus, the annual temperature gradient restratification 

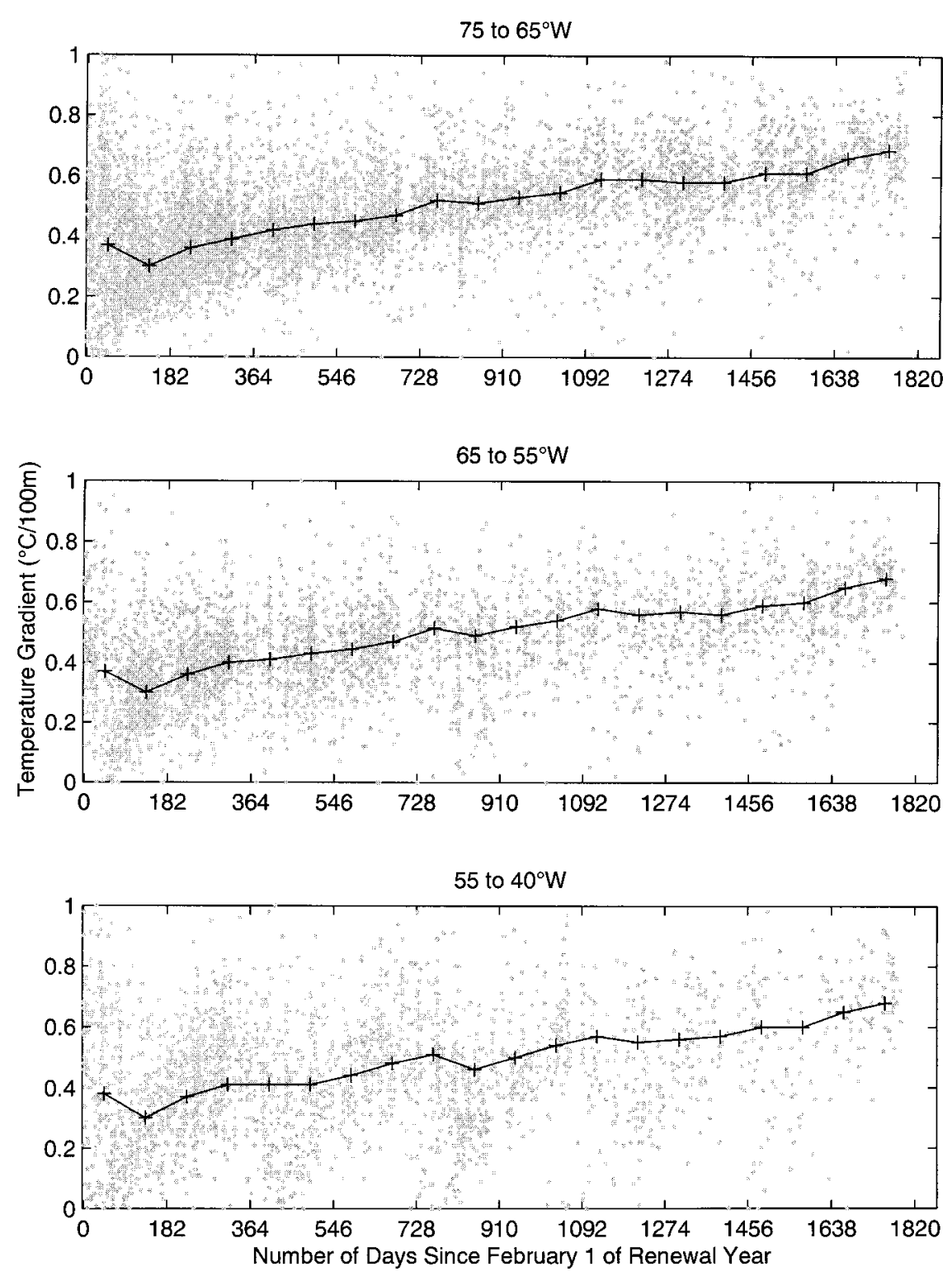

FIG. 10. Temperature gradient time series. Each cluster's mean temperature gradient through the STMW layer is plotted relative to $1 \mathrm{Feb}$ of the year the STMW layer was last renewed. The solid line represents the 90-day running median.

rate west of $55^{\circ} \mathrm{W}$ is larger for the renewal years than for the nonrenewal years.

\section{Interannual changes in the STMW layer}

Interannual changes in the STMW layer are addressed via scatter plots of time versus the temperature gradient (Fig. 10) and depth and temperature of the top of the STMW layer (Figs. 11 and 12). Time along the $x$ axis of these figures is relative to 1 February of the most recent year in which the STMW layer was renewed. The renewal years were again defined as 1969, 1970, 1977, 1980,1981 , and 1985, while the nonrenewal years were 1971, 1972, 1973, 1974, 1982, 1983, and 1986. So, clusters/profiles from 1971, 1972, 1973, and 1974 are all plotted relative to 1 February 1970.

In Fig. 10, the wide range of temperature gradients in February-April of the renewal years (days 0-90) is indicative of the three STMW configurations discussed in section 2 b. The small (e.g., $<0.3^{\circ} \mathrm{C}$ per $100 \mathrm{~m}$ ) temperature gradients are of newly formed STMW layers, while the larger temperature gradients (e.g., $>0.6^{\circ} \mathrm{C}$ per $100 \mathrm{~m}$ ) are from older STMW layers that are under the deepening winter mixed layer. In the two westernmost regions, the increase in the temperature gradient with time since the STMW layer was last renewed is evident.

Although the temperature gradient (Fig. 10) shows a steady increase in time for a number of years past the 

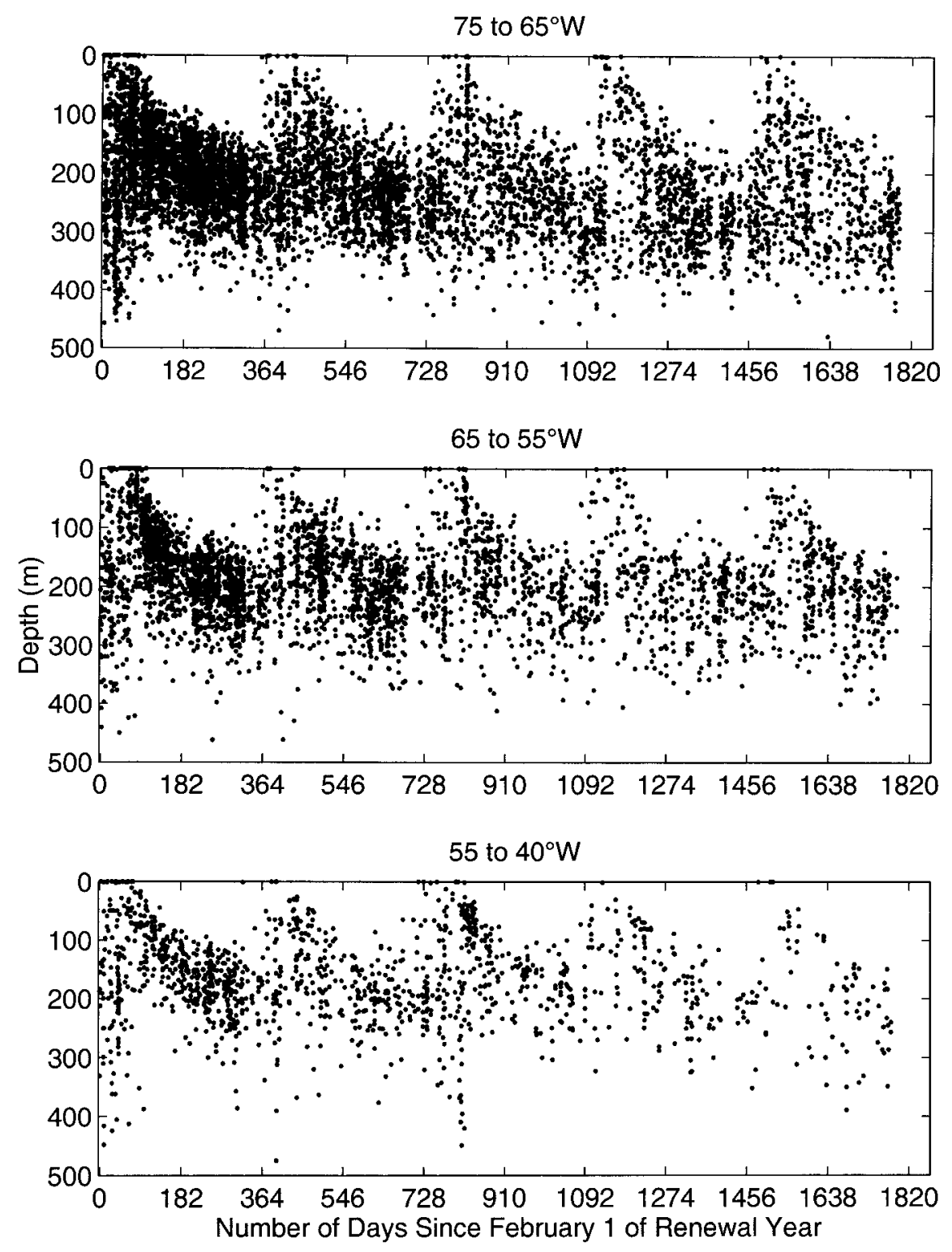

FIG. 11. Depth of top of STMW layer time series. The depth of the top of each cluster's STMW layer is plotted relative to $1 \mathrm{Feb}$ of the year the STMW layer was last renewed.

most recent renewal of the STMW layer, the depth of the top of the STMW layer (Fig. 11) shows an annual shoaling to the sea surface in February-April, including the nonrenewal years. This would imply the STMW layer was exposed to direct atmospheric cooling and convective mixing. However, Fig. 12 shows several profiles with warm temperatures $\left(>19^{\circ} \mathrm{C}\right)$ at the top of the STMW layer in spring, particularly west of $65^{\circ} \mathrm{W}$ and in the fourth and fifth years (days $>1100$ ) after renewal. This, taken with the relatively few profiles with small $\left(<0.4^{\circ} \mathrm{C}\right.$ per $\left.100 \mathrm{~m}\right)$ temperature gradients in these springs, suggests that multiple-layer STMW layers may have formed during these nonrenewal years, particularly west of $65^{\circ} \mathrm{W}$. These dual-layer STMW layers consist of a shallow, warm STMW layer, which was locally formed in that winter on top of an older STMW layer that was formed in a previous winter, as discussed in section 3c. Again, the method used here (Alfultis and Cornillon 2001) has difficulty distinguishing between these two layers. Therefore, both layers would be grouped into one layer, resulting in the shoaling of the top of the STMW layer in Fig. 11, the increase in profiles with warm temperatures at their top in Fig. 12, and the lack of corresponding profiles with small temperature gradients in Fig. 10 (the temperature gradients plotted in Fig. 10 were the slope of the best-fit line through both layers). This correspondence between small temperature gradients and the shoaling of the STMW layer 

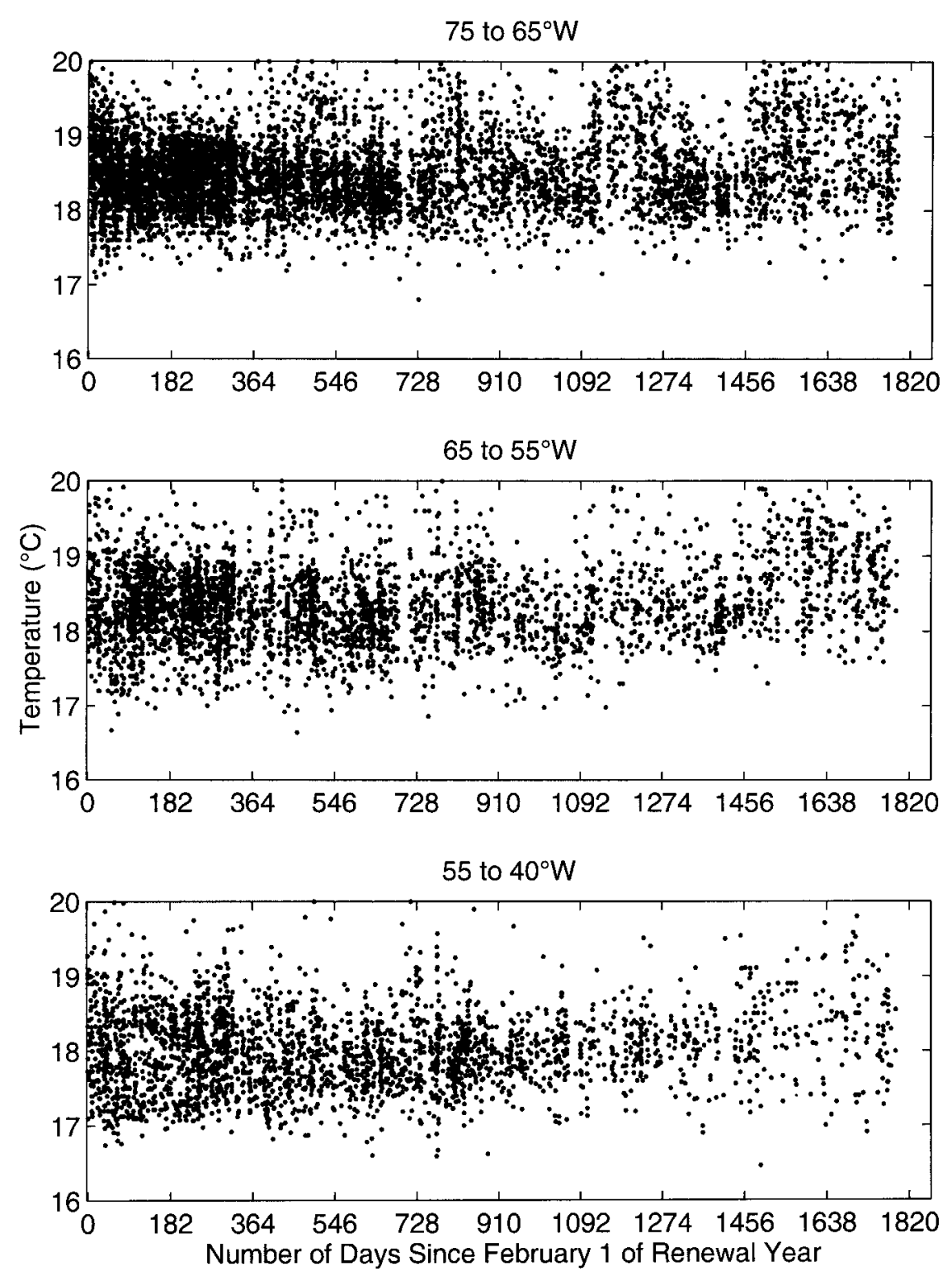

FIG. 12. Temperature at top of STMW layer time series. The temperature at the top of each cluster's STMW layer is plotted relative to $1 \mathrm{Feb}$ of the year the STMW layer was last renewed.

with warm temperatures at its top is less evident in the $65^{\circ}-55^{\circ} \mathrm{W}$ region than west of $65^{\circ} \mathrm{W}$, probably due to a complex mixture of locally formed deep, locally formed shallow, and advected STMW layers.

Finally, Figs. 10, 11, and 12 again indicate that the STMW layer in the region east of $55^{\circ} \mathrm{W}$ is renewed more often than west of $55^{\circ} \mathrm{W}$. East of $55^{\circ} \mathrm{W}$, the annual resetting of the temperature gradient to smaller values is seen in subsequent years ( $\sim$ days $370,730,1100$, 1460). The top of the STMW layer again shoals each spring ( $\sim$ days $370,730,1100,1460)$, but there are relatively fewer profiles with warm temperatures $\left(>19^{\circ} \mathrm{C}\right)$ at the top of the STMW layer in this region each spring than there are in the other two regions.
In order to quantify the STMW layer temperature gradient's interannual restratification rate, the median temperature gradient in Fig. 10, STMW layer thickness, and temperature difference through the STMW layer were found every 90 days for the two regions west of $55^{\circ} \mathrm{W}$. To separate these seasonal changes of the STMW layer from the interannual changes, a least squares line was fit to the November-January median temperature gradient and STMW layer thickness and temperature difference. By November, the seasonal pynocline would be at its maximum depth, and the reversal of the buoyancy forcing would not yet have completely removed the seasonal pycnocline for the November-January period. Table 3 lists the interannual rates of change for 

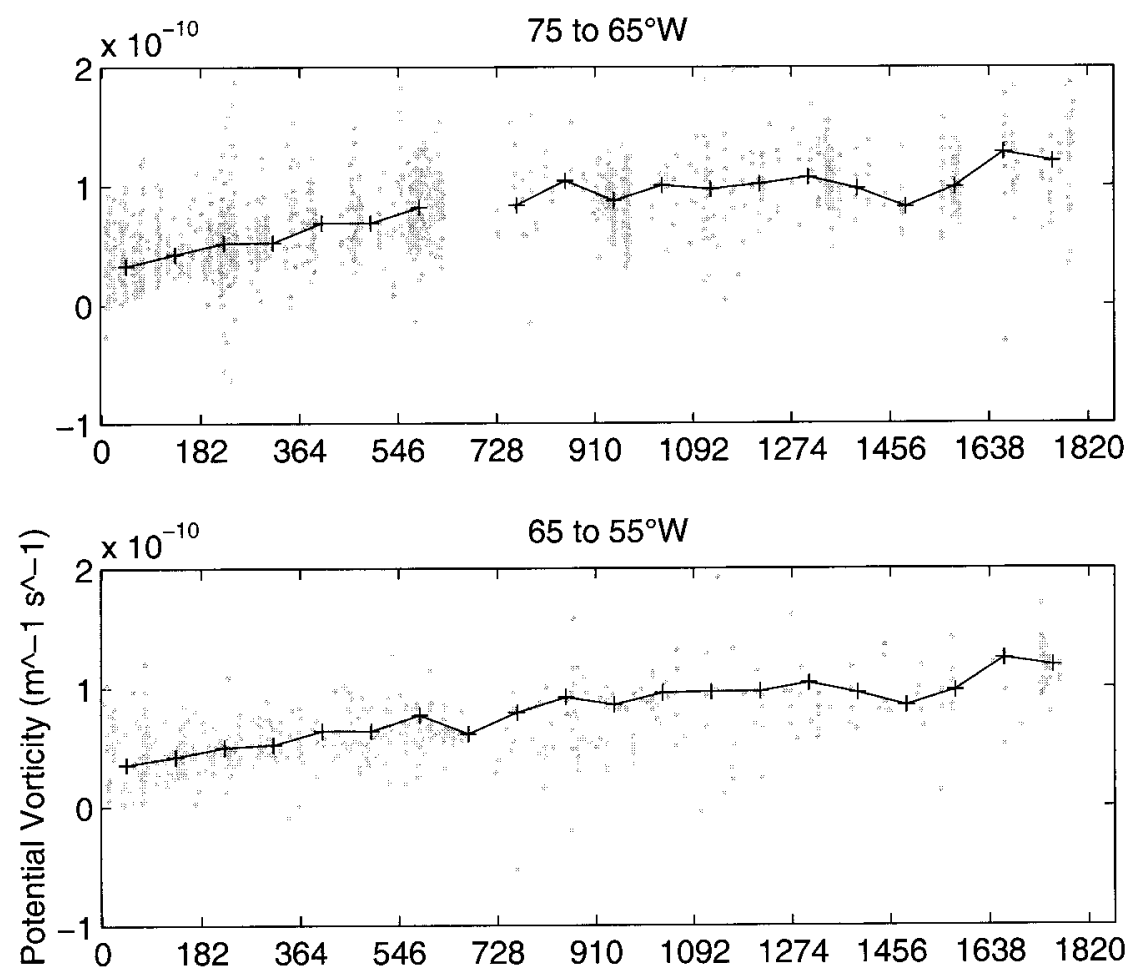

FIG. 13. Potential vorticity time series. Each cluster's mean potential vorticity through the STMW layer is plotted relative to $1 \mathrm{Feb}$ of the year the STMW layer was last renewed. The solid line represents the 90 -day running median.

the temperature gradient, thickness, and temperature difference, as determined from the slopes of these best-fit lines. Comparing Tables 2 and 3, the interannual restratification rate is smaller than the annual restratification rate for renewal years, while the interannual restratification rate is similar to the annual restratification rate for nonrenewal years west of $65^{\circ} \mathrm{W}$. From Table 3, it appears that changes in thickness (thinning) as well as temperature difference (increasing) cause the temperature gradient through the STMW layer to increase during years of no renewal.

Figure 13 shows the change in the potential vorticity of the STMW layer (calculated from hydrographic station and CTD data) with time since the STMW layer was last renewed. The solid line represents the median potential vorticity every 90 days. Although there are fewer data points and the change of potential vorticity with time is noisier than the change in temperature gradient, the trend in Fig. 13 for potential vorticity is similar to the trend in Fig. 10 for temperature gradient; the potential vorticity (i.e., density stratification) of the STMW layer increases when the STMW layer experiences no convective mixing and renewal. Talley and Raymer (1982) examined the interannual variability in the STMW arriving at the Panulirus hydrographic station near Bermuda. They also found the potential vorticity (i.e., the potential density gradient) at the potential vorticity minimum within the STMW layer increased from 1972 to 1975 . They argued that this increase was because the STMW arriving at Panulirus had not been renewed since 1971 and the STMW layer was becoming thinner during the years of no annual renewal.

The slow relaxation of the STMW layer stratification seen here is also consistent with other observations and numerical model results. STMW formed in a particular winter seems to lose its distinguishing characteristics two years after its formation (Jenkins 1982; Suga et al. 1989). Hazeleger and Drijfhout (1998) found, using an isopycnal model of the North Atlantic subtropical gyre coupled with a mixed layer model, that it took five years to attenuate a positive thickness anomaly introduced into the STMW layer during an anomalously cold winter. The mechanism(s) responsible for the dissipation of the STMW layer within a few years of its formation are not known. Hazeleger and Drijfhout argued that this slow attenuation was due to the anomalously strong stratification induced by the severe wintertime cooling followed by the return of the seasonal pycnocline. This stronger than normal stratification allowed the thickness anomaly to persist for several years following its formation. Several authors have suggested the STMW layer experiences turbulent vertical mixing as it is advected around the subtropical gyre (Warren 1972; McCartney 1982). Suga et al. (1989) and Bingham (1992) suggest that the bottom of the North Pacific STMW layer undergoes diapycnal mixing with the main thermocline. 
Suga and Hanawa (1995) found indications of mixing by salt fingering at the core and bottom of the North Pacific STMW layer. Dewar (1986) developed a model of the STMW layer that suggests the potential vorticity structure in the layer is maintained by diabatic potential vorticity forcing during wintertime convection and lateral eddy-driven mixing. Hazeleger and Drijfhout (1998) found, using their isopycnal model of the North Atlantic subtropical gyre coupled with a mixed layer model, that diapycnal diffusion and lateral viscosity to be unimportant, however.

\section{Conclusions}

Three different characterizations were used to assess the degree of renewal of the STMW layer during the 1968-88 winters. Two characterizations are based on comparing the winter mixed layer properties to the STMW layer properties in the previous fall, while the third characterization involves comparing the temperature gradient through the STMW layer in the fall before convective mixing to the temperature gradient in the spring after convective mixing. The characterizations are statistically correlated and in good agreement, with the exceptions of 1975, 1976, and 1979 and the years of poor sampling in February through April.

The mixed layer characterizations are dependent on sampling the deep, cold mixed layers when and where the convective mixing is taking place. The temperature gradient characterization has the advantage of being less time sensitive, but it is susceptible to advection of the profiles from the actual location of the convective mixing, making it difficult to determine whether STMW was locally renewed or not. In addition, the temperature gradient criterion is affected by the formation of duallayer STMW layers during winters of partial renewal, indicating renewal of the STMW layer when there was little penetration of the winter mixed layers into the STMW layer.

The characterizations are in good agreement with previous studies of STMW using a variety of characterizations. The three characterizations developed here, which are based on temperature alone however, take advantage of the large number of XBT profiles to describe the variations in the renewal of the STMW layer in space as well as time. The results found here show significant spatial as well as temporal variations in the degree of STMW renewal. The mixed layer seems to penetrate into the STMW layer more often and typically for a longer period each year in the eastern portion of the subtropical gyre than in the western portion. Since the boundaries for the three regions examined in this study $\left(75^{\circ}-65^{\circ} \mathrm{W}, 65^{\circ}-55^{\circ} \mathrm{W}\right.$, and $\left.55^{\circ}-40^{\circ} \mathrm{W}\right)$ were chosen based on the distribution of the data and to prevent biasing of the results toward the west (versus choosing these regions based on physical considerations), we cannot reliably define $55^{\circ} \mathrm{W}$ as the boundary for the region of frequent STMW renewal, nor can we specify the dominant temporal and spatial scales for convective mixing and renewal of the STMW layer in winter.

Most of the annual restratification following winters of STMW renewal is due to annual decreases in thickness, with a slight increase in the temperature difference aiding in increasing the temperature gradient through the layer. Although the annual deepening of the mixed layer and reentrainment of waters at the top of the STMW layer may explain much of the annual changes in thickness, it cannot explain the increase in the temperature difference. If the waters at the top of the STMW layer were simply reentrained with no other processes acting on the layer, the temperature difference through the layer would decrease as the seasonal pycnocline worked its way down the STMW layer temperature gradient. However the temperature difference is increasing. This increase in the temperature difference could be due to

1) vertical mixing/diffusion of relatively warmer water down from above the layer and/or

2) vertical mixing/diffusion of relatively cooler water up from beneath the layer and/or

3) lateral processes bringing warmer/cooler water into the STMW layer

(McCartney 1982; Dewar 1986; Suga et al. 1989; Bingham 1992; Suga and Hanawa 1995). In addition, the annual rate of increase in the temperature difference through the STMW layer in renewal years [2.2 to 4.4 $\left(\times 10^{-4} \mathrm{C}\right.$ per day) in the $75^{\circ}-65^{\circ} \mathrm{W}$ region and 4.4 to $5.6\left(\times 10^{-4 \circ} \mathrm{C}\right.$ per day $)$ in the $65^{\circ}-55^{\circ} \mathrm{W}$ region; Alfultis (1997)] and the interannual rate of increase in the temperature difference following winters of no renewal ( $\mathrm{Ta}-$ ble 3) are of the same order, suggesting that similar processes (horizontal/vertical mixing/diffusion and/or horizontal advection) are affecting the change in temperature through the STMW layer on annual and interannual scales. However, different processes appear to be affecting the decrease in the thickness of the STMW layer on annual and interannual timescales. The thickness of the STMW layer decreases at a rate of $\sim 0.2-$ $0.3 \mathrm{~m}$ per day from $\sim$ June to $\sim$ December following a winter in which the STMW layer experienced convective mixing and renewal (Alfultis 1997). These rates are an order of magnitude larger than the interannual rates given in Table 3, resulting in the annual restratification rate following a winter of convective renewal being larger than the interannual restratification rate following winters of little or no renewal. The annual decrease in the thickness of the STMW layer is again most likely dominated by the deepening of the seasonal thermocline from May to December. The interannual decrease in the thickness of the STMW layer (i.e., differences in NovJan thickness of the STMW layer) following winters of no STMW renewal may be due to Ekman pumping and/ or subduction of the STMW layer between thinning isopycnals. These compressional processes would also be working on the STMW layer on annual (May-Dec) timescales but may not be as significant as the deepening 
of the seasonal thermocline on these shorter timescales. Although characterizing the STMW layer using a temperature-based criteria allowed us to take advantage of the large volumes of XBT data, we could not address the role/importance of annual and interannual variations in salinity on the structure of the STMW layer. Joyce and Robbins (1996) found that, while the temperature and salinity anomalies in the surface layer $(0-200 \mathrm{~m})$ at the Panulirus station lacked correlation, periods of positive salinity anomaly in the surface layer (0-200 m) corresponded to periods of low potential vorticity (renewal) of the STMW layer, suggesting that variations in surface salinity play some role in the interannual variability of the STMW layer. In addition, the STMW formation region is also a relatively high energy region of the subtropical gyre (Rossby et al. 1986; Shen et al. 1986; Taft et al. 1986), and the modification of the STMW-layer stratification by small scale dynamical features such as eddies and rings (e.g., Brundage and Dugan 1986; Ebbesmeyer and Lindstrom 1986) could not be distinguished here from the influence of convective mixing on the STMW-layer stratification. Finally, the data distribution prevents us from determining the dominant temporal and spatial scales for the convective mixing and renewal of the STMW layer in winter.

Acknowledgments. We wish to acknowledge the support of the U.S. Coast Guard and David Adamec of NASA Goddard Space Flight Center. We thank Ken Casey for the development and use of his clustering program. Comments by the two anonymous reviewers were particularly helpful in improving the manuscript.

\section{REFERENCES}

Alfultis, M., 1997: Statistical characterizations of North Atlantic Subtropical Mode Water. Ph.D. dissertation, University of Rhode Island, $161 \mathrm{pp}$.

__ and P. Cornillon, 2001: A characterization of the North Atlantic STMW layer climatology using World Ocean Atlas 1994 data. J. Atmos. Oceanic Technol., in press.

Bingham, F. M., 1992: Formation and spreading of subtropical mode water in the North Pacific. J. Geophys. Res., 97, 11 177-11 189.

Boyer, T., and S. Levitus, 1994: Quality control and processing of historical oceanographic temperature, salinity, and oxygen data. NOAA Tech. Rep. NESDIS 81, 64 pp.

Brundage, W. L., and J. P. Dugan, 1986: Observations of an anticyclonic eddy of $18^{\circ} \mathrm{C}$ Water in the Sargasso Sea. J. Phys. Oceanogr., 16, 717-727.

Cayan, D. R., 1992: Latent and sensible heat flux anomalies over the northern oceans: Driving the sea surface temperature. J. Phys. Oceanogr., 22, 859-881.

Cornillon, P., C. Gilman, L. Stramma, O. Brown, R. Evans, and J. Brown, 1987: Processing and analysis of large volumes of satellite-derived thermal infrared data. J. Geophys. Res., 92, 12 993-13 002.

Dewar, W. K., 1986: On the potential vorticity structure of weakly ventilated isopycnals: A theory of subtropical mode water maintenance. J. Phys. Oceanogr., 16, 1204-1216.

Dickson, R., J. Lazier, J. Meincke, R. Rhines, and J. Swift, 1996 Long-term coordinated changes in the convective activity of the
North Atlantic. Progress in Oceanography, Vol. 38, Pergamon 241-295.

Ebbesmeyer, C., and E. Lindstrom, 1986: Structure and origin of $18^{\circ} \mathrm{C}$ Water observed during the POLYMODE local dynamics experiment. J. Phys. Oceanogr., 16, 443-453.

Gong, X., and M. B. Richman, 1995: On the application of cluster analysis to growing season precipitation data in North America east of the Rockies. J. Climate, 8, 897-931.

Hall, M. M., and N. P. Fofonoff, 1993: Downstream development of the Gulf Stream from $68^{\circ}$ to $55^{\circ}$ W. J. Phys. Oceanogr., 23, 225249.

Hallock, Z., and W. Teague, 1992: The fall rate of the T-7 XBT. $J$. Atmos. Oceanic Technol., 9, 470-483.

Hanawa, K., and H. Yoritaka, 1987: Detection of systematic errors in XBT data and their correction. J. Oceanogr. Soc. Japan, 43, 68-76.

__ in the Kuroshio region over the Izu Ridge. J. Mar. Res., 46, 683-700.

_- , and Y. Yoshikawa, 1991: Reexamination of the depth error in XBT data. J. Atmos. Oceanic Technol., 8, 422-429.

__ P. Rual, R. Bailey, A. Sy, and M. Szabados, 1995: A new depthtime equation for Sippican or TSK T-7, T-6, and T-4 expendable bathythermographs (XBT). Deep-Sea Res., 42, 1423-1451.

Hazeleger, W., and S. Drijfhout, 1998: Mode water variability in a model of the subtropical gyre: Response to anomalous forcing. J. Phys. Oceanogr., 28, 266-288.

Istoshin, Y., 1961: Formative area of 'eighteen-degree' water in the Sargasso Sea. Deep-Sea Res., 9, 384-390.

Jenkins, W., 1982: On the climate of the subtropical gyre: Decade timescale variations in water mass renewal in the Sargasso Sea. J. Mar. Res., 40 (Suppl.), 265-290.

_- 1998: Studying thermocline ventilation and circulation using Tritium and ${ }^{3}$ He. J. Geophys. Res., 103, 15 817-15 831.

Joyce, T. M., and P. Robbins, 1996: The long-term hydrographic record at Bermuda. J. Climate, 9, 3121-3131.

Klein, B., and N. Hogg, 1996: On the interannual variability of 18 Degree Water formation as observed from moored instruments

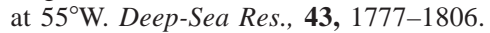

Lappo, S., G. Alekseev, and V. Effimov, 1995: On oceanological results of the program sections. Atmos. Oceanic Phys., 31, 373384.

Leetmaa, A., 1977: Effects of the winter of 1976-1977 on the northwestern Sargasso Sea. Science, 198, 188-189.

Marsh, R., and A. L. New, 1996: Modeling $18^{\circ}$ Water variability. $J$. Phys. Oceanogr., 26, 1059-1080.

McCartney, M., 1982: The subtropical recirculation of Mode Waters. J. Mar. Res., 40 (Suppl.), 427-464.

_ L. Worthington, and M. Raymer, 1980: Anomalous water mass distributions at $55^{\circ} \mathrm{W}$ in the North Atlantic in 1977. J. Mar. Res., 38, 147-172.

Paiva, A. M., and E. P. Chassignet, 2000: Modeling low frequency variability in North Atlantic Mode Water formation. U.S. WOCE Implementation Rep. 12, 47-50.[Available from U.S. WOCE Office, Department of Oceanography, Texas A\&M University, College Station, TX 77843-3146.]

Qiu, B., and T. Joyce, 1992: Interannual variability in the mid- and low-latitude western North Pacific. J. Phys. Oceanogr., 22, 1062-1079.

Roemmich, D., and B. Cornuelle, 1992: The subtropical mode waters of the South Pacific Ocean. J. Phys. Oceanogr., 22, 1178-1187.

Rossby, T., J. Price, and D. Webb, 1986: The spatial and temporal evolution of a cluster of SOFAR floats in the POLYMODE Local Dynamics Experiment (LDE). J. Phys. Oceanogr., 16, 428-442.

Schroeder, E., H. Stommel, D. Menzel, and W. Sutcliffe Jr., 1959: Climatic stability of Eighteen Degree Water at Bermuda. J. Geophys. Res., 64, 363-366.

Shen, C. Y., J. C. McWilliams, B. A. Taft, C. C. Ebbesmeyer, and E. J. Lindstrom, 1986: The mesoscale spatial structure and evolution of dynamical and scalar properties observed in the north- 
western Atlantic Ocean during the POLYMODE Local Dynamics Experiment. J. Phys. Oceanogr., 16, 454-482.

Singer, J., 1990: On the error observed in electronically digitized T7 XBT data. J. Atmos. Oceanic Technol., 7, 603-611.

Suga, T., and K. Hanawa, 1990: The mixed layer climatology in the north-western part of the North Pacific subtropical gyre and the formation area of Subtropical Mode Water. J. Mar. Res., 48, $543-566$.

__ and __, 1995: Subtropical mode water south of Honshu, Japan in the spring of 1988 and 1989. J. Oceanogr., 51, 1-19. —- and Y. Toba, 1989: Subtropical mode water in the $137^{\circ} \mathrm{E}$ Section. J. Phys. Oceanogr., 19, 1605-1618.

Taft, B. A., E. J. Lindstrom, C. C. Ebbesmeyer, C. Y. Shen, and J. C. McWilliams, 1986: Water mass structure during the POLYMODE Local Dynamics Experiment. J. Phys. Oceanogr., 16, 403-426.
Talley, L., and M. Raymer, 1982: Eighteen Degree Water variability. J. Mar. Res., 40 (Suppl.), 757-775.

Warren, B., 1972: Insensitivity of subtropical mode water characteristics to meteorological fluctuations. Deep-Sea Res., 19, 1-19.

Woods, J., and W. Barkmann, 1986: A lagrangian mixed layer model of Atlantic $18^{\circ}$ water formation. Nature, 319, 574-576.

Worthington, L., 1959: The $18^{\circ}$ water in the Sargasso Sea. Deep-Sea Res., 5, 297-305.

__ 1977: Intensification of the Gulf Stream after the winter of 1976-77. Nature, 270, 415-417.

Yasuda, T., and K. Hanawa, 1997: Decadal changes in the mode waters in the midlatitude North Pacific. J. Phys. Oceanogr., 27, $858-870$.

__ and __ 1999: Composite analysis of North Pacific Subtropical Mode Water properties with respect to the strength of the wintertime East Asian monsoon. J. Oceanogr., 55, 531-541. 